\title{
Experimental Investigation on Lateral Impact Response of Concrete-Filled Double-Skin Tube Columns using Horizontal-Impact-Testing System
}

\author{
S. Aghdamy ${ }^{1}$ *, D. P. Thambiratnam ${ }^{1}$, M. Dhanasekar ${ }^{1}$
}

\begin{abstract}
This paper presents an experimental investigation on the lateral impact performance of axially loaded concretefilled double-skin tube (CFDST) columns. These columns have desirable structural and constructional properties and have been used as columns in building, legs of off shore platforms and as bridge piers. Since they could be vulnerable to impact from passing vessels or vehicles, it is necessary to understand their behaviour under lateral impact loads. With this in mind, an experimental method employing an innovative instrumented horizontal impact testing system (HITS) was developed to apply lateral impact loads whilst the column maintained a static axial pre-loading to examine the failure mechanism and key response parameters of the column. These included the time histories of impact force, reaction forces, global lateral deflection and permanent local buckling profile. Eight full scale columns were tested for key parameters including the axial load level and impact location. Based on the test data, the failure mode, peak impact force, impact duration, peak reaction forces, reaction force duration, column maximum and residual global deflections and column local buckling length, depth and width under varying conditions are analysed and discussed. It is evident that the innovative HITS can successfully test structural columns under the combination of axial pre-loading and impact loading. The findings on the lateral impact response of the CFDST columns can serve as a benchmark reference for their future analysis and design.
\end{abstract}

Keywords: Experimental testing; Lateral impact; Concrete-filled double-skin tube (CFDST); Horizontal impact testing system; Axial pre-loading.

\footnotetext{
${ }^{1}$ School of Civil Engineering and Built Environment, Queensland University of Technology (QUT), Brisbane, Australia

*Corresponding author.

E-mail: s.aghdamy@qut.edu.au
} 


\section{Introduction}

Concrete-filled double-skin tubes (CFDSTs) consist of two concentric steel tubes separated by a concrete filler. They have been used for nearly two decades as legs of offshore platforms [1] to mitigate stability concerns in hollow steel tubes. More recently, CFDSTs have been used as a new sustainable alternative to existing structural bridge piers [2] to reduce structural weight and enhance energy absorption under seismic loads. They have also been used as transmission towers [3] where they provide savings in material and construction costs. Due to their predominant usage in civil infrastructure, CFDSTs are susceptible to lateral impacts which may result from collision of vehicles or moving ice sheet or flying debris from a nearby explosion. Unfortunately, there is a paucity of literature on the experimental studies on the lateral impact of CFDSTs.

Corbett et al. [4] conducted an experimental study on small scale CFDSTs to investigate their response to high velocity projectile impacts. The impact load was applied by means of a hemispherical projectile fired from a compressed air gun. The test results indicated highly localised circular shape dents on the outer tube and axially extended dent on the inner tube. Recently, Li et al. [5] numerically investigated the impact response of simply supported (i) hollow steel tubes, (ii) concrete-filled hollow steel tubes and (iii) CFDSTs for use in oil and gas pipeline applications. Results showed that the maximum global displacement and indentation depth and area of CFDSTs were smaller than those of the other tubes. More recently, Wang et al. [6] assessed the lateral impact performance of double skin tubes filled with ultra-light weight cement composite (ULCC) through drop weight impact tests and numerical simulations. The results indicated superior impact performance with higher impact resistance, smaller global deformation and local indentation of CFDST members compared to steel hollow tubes. The ULCC layer effectively limits the development of the local indentation.

The studies mentioned above indicate that CFDST members have good impact resistance, in general. However, these studies are among the first on this topic, limited in scope and their conclusions are preliminary. It is believed that further experimental investigation is required to develop a comprehensive understanding of the impact performance of these columns for the development of practical design methods. Additionally, there is a need to evaluate the lateral impact performance of CFDSTs when used as axially loaded columns as existing studies have not yet taken into account the effect of axial loads. In the studies that have been undertaken so far, the lateral impact load was considered at the mid-span. However, column mid-span is not the most likely place for an impact to occur. When a column is located at the frontage of buildings for example, an impact (such as vehicular impact) is more likely to occur nearer the ground level rather than at the mid-point. 
To experimentally study the impact response of structural members, two techniques have been widely adopted by researchers. These are the swinging pendulum test [7-9] and free fall drop weight test [10-16,6]. The pendulum test rig involves a supporting frame and a swinging pendulum which can be made to impact a specimen in its path. The free fall test rig involves an impact tower with two vertical columns guiding a hammer, which can be raised to a predetermined height by a hoist and chain system. The hammer positioned at the specified height is allowed to fall freely and impact a specimen at right angles. The drop-weight testing method has the advantage of having inherent fail-safe characteristics in the event of unanticipated complete failure of the specimen, as the vertical motion of the hammer can be arrested by anvil seated on the string floor [17]. Although this test rig is more compact than the swinging pendulum, to effectively increase the impact energy and the strain rate, it requires increasing the impact velocity by increasing the height of the free fall which implies increasing the height of the tower.

Furthermore, in designing an impact experiment where the effect of axial pre-loading is considered, the test rig should be capable of applying and maintaining the axial pre-loading during the impact. This is due to the fact that the axial load which is applied to offshore platform legs, bridge piers and building columns could be regarded as nearly constant during the impact process [18]. Allan, Marshall [19] carried out a series of tests on axially loaded steel tubes subjected to dynamic lateral impact. They used a hydraulic ram to apply the axial load and reported that the applied axial pre-loading eventually vanished during the impact due to column axial shortening. To overcome the difficulties which Allen and Marshal had in their tests, Zeinoddini et al. [18] introduced a selfreacting system containing a relatively long length of disc-springs. In their tests, the high strength steel tube specimen had a rigid support at one end but was allowed free translation in the axial direction at the other end. The sliding support allowed the axial load to be applied to the specimen and for shortening to occur as a result of the impact. Hence, the springs were stacked behind the sliding end of the specimen. Their results showed that the springs were able to recover a major portion of the loss of axial loading. Another technique for applying axial load was proposed by Yousuf et al. [20] where a pre-tensioning system consisting of steel plates, threaded steel rods, nuts and bolts was used to apply axial load to steel tubes and concrete-filled tubes under lateral impact. They passed a steel rod through the columns and tightened it by a nut which was attached to the rod at each end. By tensioning the rod, the column is kept in compression. Whilst this technique requires less space and can maintain the axial load at a constant level, the presence of the rod in the column can affect its impact response. 
This paper presents an intensive experimental investigation on the response of CFDST columns subjected to combined static axial pre-loading and lateral impact loading. It describes, in detail, the experimental test programme which makes use of an in-house developed innovative, compact, repeatable and cost-effective horizontal impact testing system (HITS) capable of delivering up to $10.40 \mathrm{~kJ}$ of impact energy and applying 1390 $\mathrm{kN}$ of axial load. A new axial loading system, using a combination of disc-springs and parallel tension-rods located on either side of the specimen (i.e., not inside the specimen) was designed to maintain the axial load during impact possess. The instrumentation used to collect data on the impact behaviour of CFDST columns is described. New experimental results on simply supported circular CFDST members under lateral impact, where the testing parameters include the axial load level as well as the impact location are presented. Based on the testing results, the typical failure modes and the time histories of the impact forces, reaction forces, axial load and local and global deflections of the CFDST columns are analysed and discussed.

\section{Experimental Program}

\section{Specimen characteristics and preparation}

The experimental program included eight CFDST specimens with circular outer and inner steel tubes. The typical CFDST section is shown in Fig 1. The specimens were $3 \mathrm{~m}$ long. The outer tubes had a nominal outside diameter $\left(D_{o}\right)$ and wall thickness $\left(t_{o}\right)$ of $165.1 \mathrm{~mm}$ and $5.4 \mathrm{~mm}$, respectively. The inner tubes had a nominal outside diameter $\left(D_{i}\right)$ and wall thickness $\left(t_{i}\right)$ of $33.7 \mathrm{~mm}$ and $4 \mathrm{~mm}$, respectively.

Tensile coupon tests carried out under conditions specified in AS 1391 (2007) [21] showed that the mean yield and ultimate strengths of outer steel tubes were 299.5 MPa and 358.5 MPa, respectively. They were 401.3 MPa and 433.4 MPa, respectively, for the inner steel tube. The concrete core had a nominal compressive strength and maximum aggregate size of $25 \mathrm{MPa}$ and $10 \mathrm{~mm}$, respectively. The mean measured unconfined compressive strength of $100 \mathrm{~mm} \times 200 \mathrm{~mm}$ concrete cylinder at the day of testing was $32.35 \mathrm{MPa}$ as determined in accordance with AS1012.9 (1999) [22].

Table 1 summarises the nominal and measured values of outside diameter and wall thickness of both outer and inner tubes. The columns were considered slender as the slenderness ratio was 71.5. 


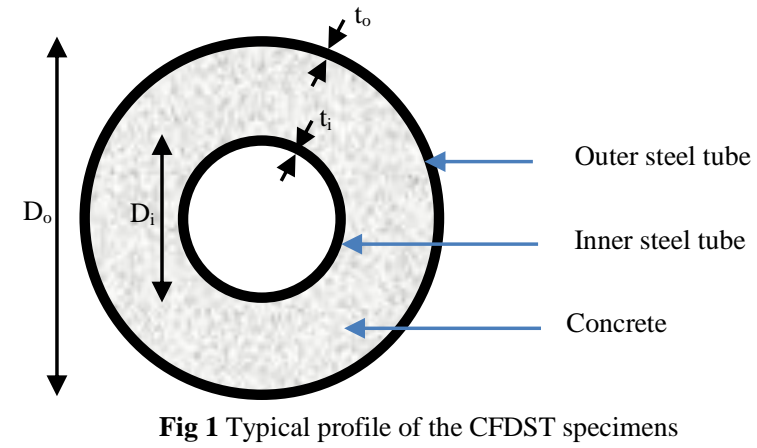

Table 1 Steel tube characteristics

\begin{tabular}{lcccc}
\hline & $\mathrm{D}_{\mathrm{o}}(\mathrm{mm})$ & $\mathrm{t}_{\mathrm{o}}(\mathrm{mm})$ & $\mathrm{D}_{\mathrm{i}}(\mathrm{mm})$ & $\mathrm{t}_{\mathrm{i}}(\mathrm{mm})$ \\
\cline { 2 - 5 } & & & & \\
Nominal & 165.10 & 5.40 & 33.70 & 4.00 \\
& & 5.39 & 33.71 & 4.00 \\
Measured (Average) & 165.80 & 5.60 & 33.80 & 4.10 \\
& 166.00 & 5.30 & 33.70 & 4.00 \\
\hline
\end{tabular}

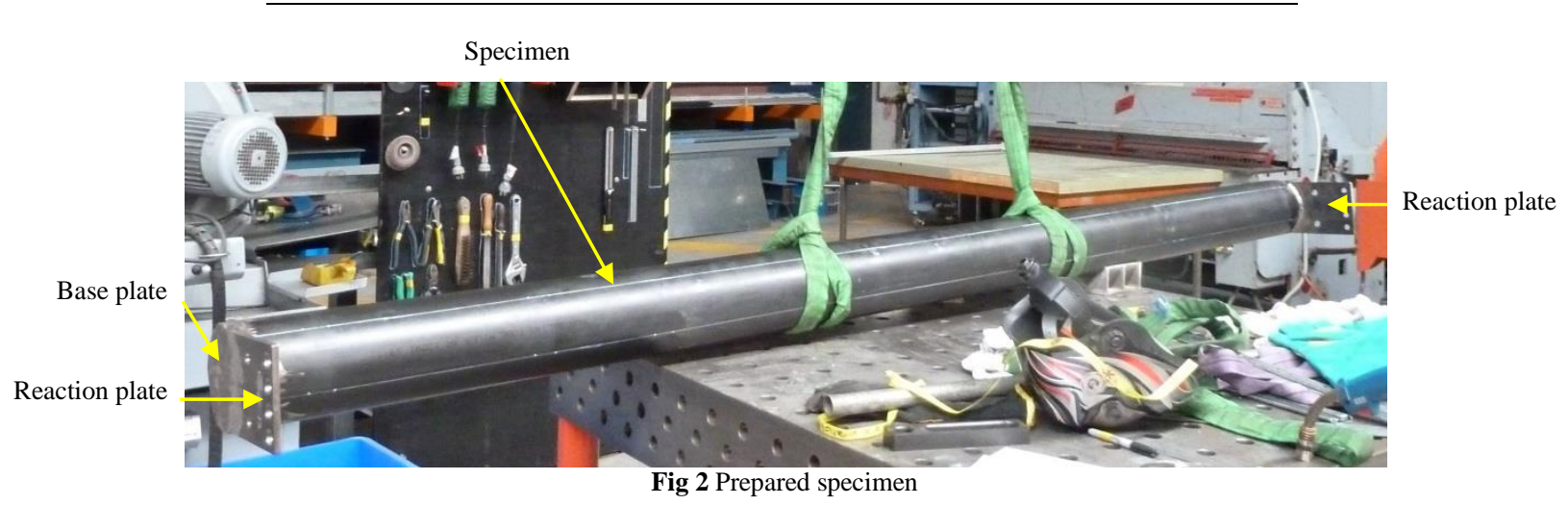

To prepare the specimens, the inner tube was first held vertically on a $10 \mathrm{~mm}$ thick steel base plate (or end plate) on a clearly marked circle and welded. The outer tube was then positioned around the inner tube, symmetrically, and welded to the same base plate. The specimens were then securely held upright and the concrete was poured from the top into the annulus between the tubes and vibrated. Plastic sheeting was then placed over the top end of the poured specimens, which were left to properly cure until testing. The longitudinal gap caused by concrete longitudinal shrinkage was filled using Sikadur 31/41 Rapid, a high-strength adhesive mortar, so that the concrete surface was flush with the steel tube at the top. Prior to testing, this surface was ground smooth to ensure the axial load could be applied evenly across the cross-section simultaneously to the steel and concrete. A $10 \mathrm{~mm}$ steel base plate was then welded to the outer tube at this end. Subsequently, a $10 \mathrm{~mm}$ reaction plate, which served to support the specimen in the direction parallel and opposite to the impact force in the tests, was welded to each base plate. Finally, the specimens were degreased and grid marked on their surfaces as shown in Fig 2. 


\section{Test matrix}

In all the impact tests, velocity and mass of the striker were kept constant and the axial pre-loading and impact location were varied. Four series of tests, with a total of eight tests, involving different combinations of axial load and impact location were conducted as shown in Table 2. To ensure repeatability of the tests, more than one specimen was tested for each series except for the first one. The considered axial pre-loadings were $0 \mathrm{kN}, 200 \mathrm{kN}$ and $400 \mathrm{kN}$, which were within a range of $0 \%, 15 \%$ and $30 \%$ of the specimen's axial capacity. The impact locations were mid-span and two-third of column length away from one of the supports. The striker mass was 262 $\mathrm{kg}$ and initial impact velocity was $7.8 \mathrm{~m} / \mathrm{sec}$. Simply supported boundary conditions were considered for all test series.

Each specimen was identified using a label, where the last two letters refer to the experiment number $(1,2,3$ or 4) and whether the specimen was the first sample $(A)$ or the repeated sample $(B$ or $C)$.

Table 2 Test matrix

\begin{tabular}{|c|c|c|c|}
\hline Test Series & Specimen & Axial Load $(\boldsymbol{k} \boldsymbol{N})$ & Impact Location \\
\hline \multirow{2}{*}{ Series \#1 } & CFDST1A & 0 & Mid-span \\
\hline & CFDST2A & 200 & Mid-span \\
\cline { 2 - 4 } & CFDST2B & 200 & Mid-span \\
\cline { 2 - 4 } & CFDST2C & 200 & Mid-span \\
\hline \multirow{2}{*}{ Series \#3 } & CFDST3A & 200 & Off-centre \\
\cline { 2 - 4 } & CFDST3B & 200 & Off-centre \\
\hline \multirow{2}{*}{ Series \#4 } & CFDST4A & 400 & Mid-span \\
\cline { 2 - 4 } & CFDST4B & 400 & Mid-span \\
\hline
\end{tabular}

\section{Horizontal impact-testing system (HITS)}

The experimental testing in this study made use of a new innovative horizontal impact testing system, which was designed, constructed and installed on the strong floor of the Banyo structures laboratory, Queensland University of Technology. The horizontal impact-testing system is shown in Fig 3. 


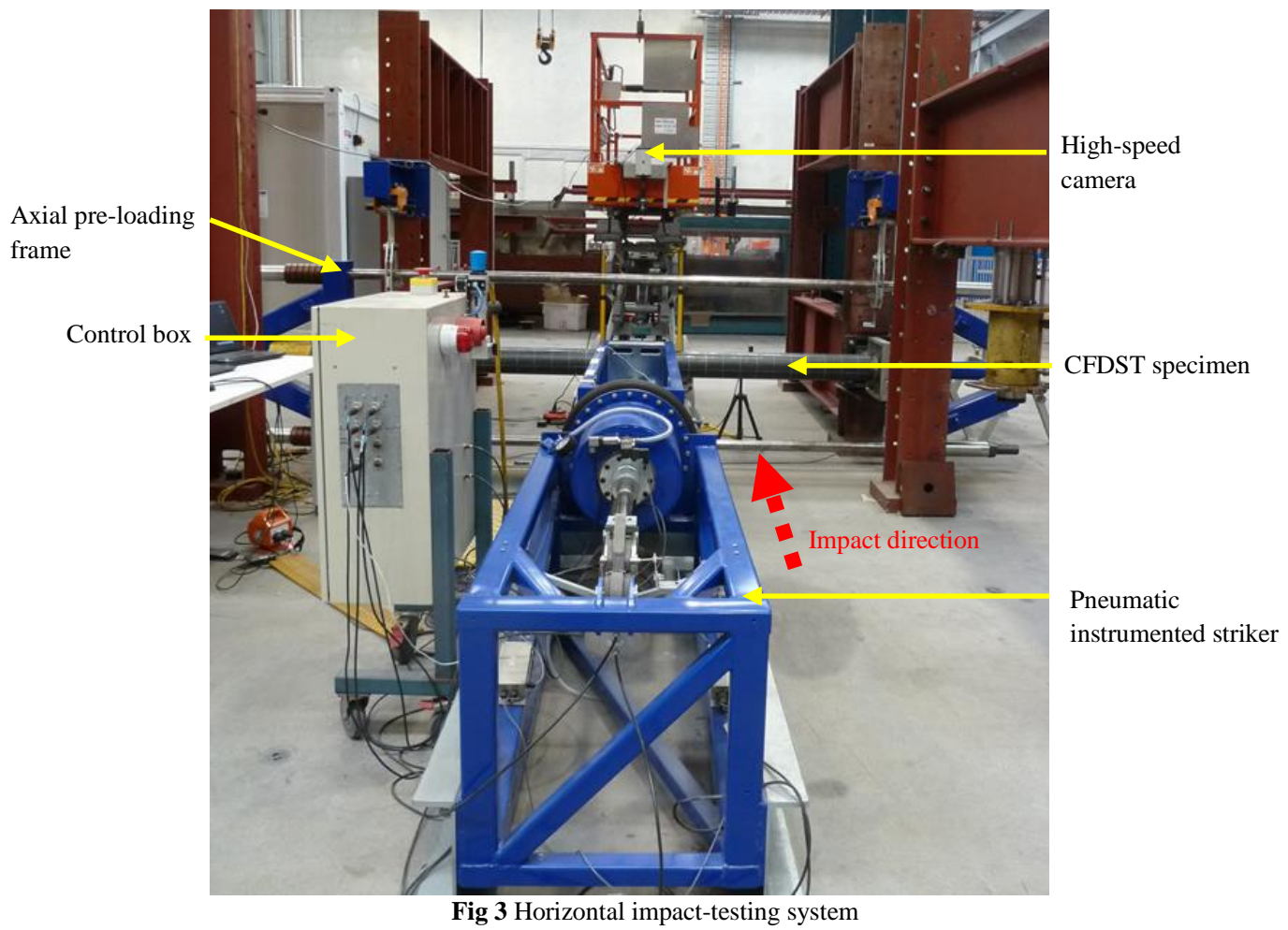

The HITS is a repeatable, efficient and cost-effective impact testing system, which greatly assists in collection of data on the fundamental behaviour of structural members subjected to impact loading. It requires less space than the drop test unit or pendulum rig and hence it is a better choice where laboratory space is limited. Using this rig, specimens of different lengths and cross sectional shapes and geometries can be tested under a combination of axial loading and lateral impacts. The HITS allows the use of interchangeable impact heads and variation in impact angle, impact energy (i.e., mass and velocity of impact), support conditions of the specimen and the level of axial pre-loading. The rig includes a pneumatic instrumented striker, an axial pre-loading frame, a specimen supports system, a control box and data measuring instruments.

\section{Pneumatic instrumented striker}

The instrumented striker shown in Fig 4 is $3.3 \mathrm{~m}$ long, $0.83 \mathrm{~m}$ wide and $0.84 \mathrm{~m}$ high. It is comprised of a frame, guide rails, an impact carriage, an actuator, a locking device, a steel crush shaft and an aluminium crush tube.

The frame, which forms the base of the horizontal sticker, is firmly fixed in place via two anchors, which are bolted to the strong floor, to increase the rig stability. The two guide rails are $2 \mathrm{~m}$ long and are $0.48 \mathrm{~m}$ apart to carry the impact carriage. The impact carriage is the only component of the striker which is able to move. Its geometrical dimensions are $1.56 \mathrm{~m} \times 0.4 \mathrm{~m} \times 0.4 \mathrm{~m}$. It is supported on the guiderails vertically and horizontally 
by six sets of three bearings (i.e., two bearings provide vertical supports and one bearing provides horizontal support.). As a result, its motion is limited to a single translation degree of freedom. The impact head, which functions as the contacting body that impacts with the test specimen, is attached to the impact end of the carriage by four mounting bolts. The striker allows utilisation of two different impact heads: (1) bullhorn nose and (2) curved. Fig 5 shows the dimensions of the curved impact head, which was used in the tests. Both of the impact heads were toughened by heat treatment. It is worth noting that the impact head used in this study did not show any sign of plastic deformation throughout the test programme. The ballasts or additional masses, which are used to control the mass of the impact body, comprise of modular steel plates that are secured on a threaded rod attached to the carriage at the back of the impact head. The steel crush shaft acts to limit the travel of the impact carriage.

The aluminium crush tube is designed to crush and absorb the remnant kinetic energy of the impact carriage once the carriage has travelled the maximum length of the steel shaft. The diameter of the tube is $50 \mathrm{~mm}$. It is $230 \mathrm{~mm}$ long and $2.8 \mathrm{~mm}$ thick.

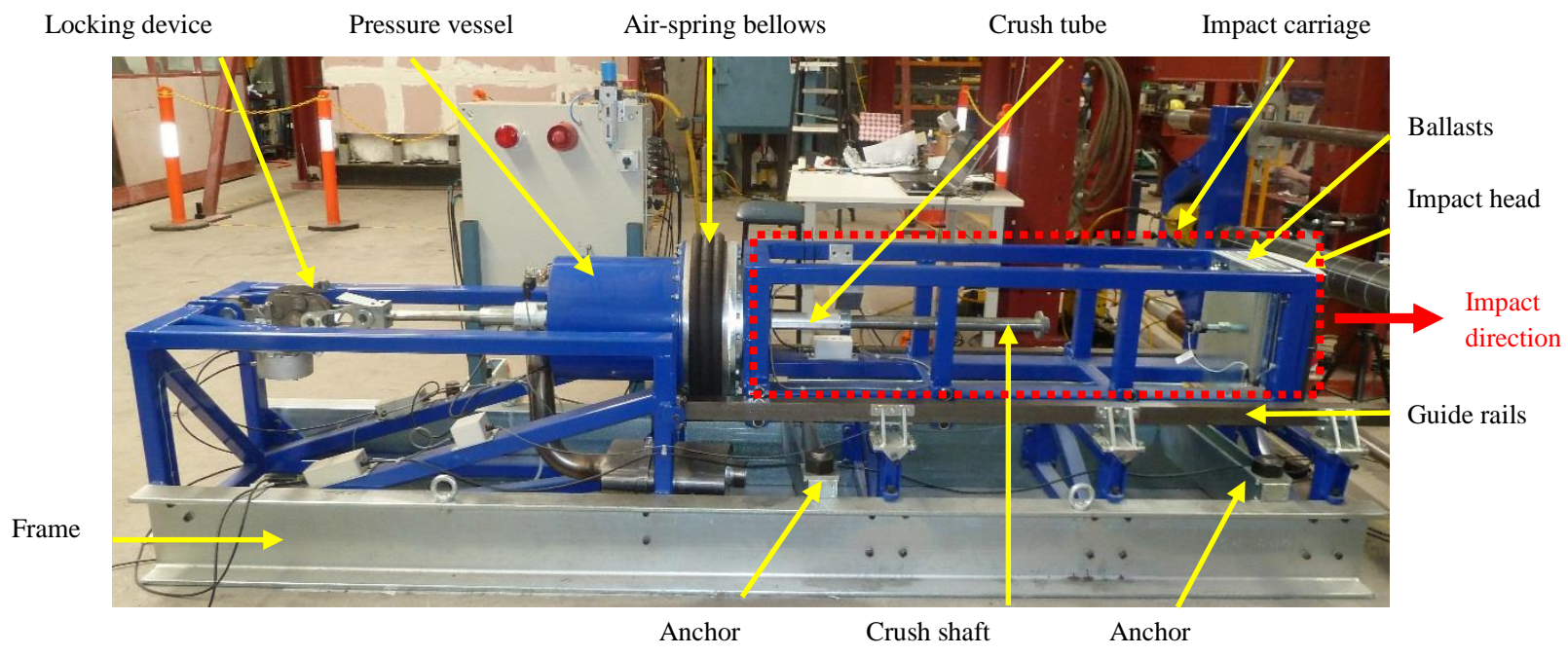

Fig 4 Pneumatic instrumented striker

The actuator consists of a pressure vessel and an attached set of expanding bellows. The pressure vessel is designed to contain up to 8 times the normal atmospheric pressure. Upon release of the locking device, the pressured air within the vessel rapidly expands the bellows. The expansion of the bellows acts to propel the impact carriage towards the test specimen. The striker with the curved impact head is capable of propelling the impact carriage with the mass of 160-325 $\mathrm{kg}$ across $555 \mathrm{~mm}$ via guided rails at velocities of up to $8 \mathrm{~m} / \mathrm{sec}$.

The locking device consists of a commercial quick release device and a steel shaft. The shaft is connected at one end to the impact side face of the bellows and features a shackle to fit the release mechanism at the other end. The 
shackle is fixed in the jaws of the release mechanism before filling of the pressure vessel. Once the pressure vessel is filled to the desired pressure, jaws are opened to release the shackle, which in turn releases the bellows.

Fig 6 shows the pneumatic instrumented striker before and after firing and hence how it operates.

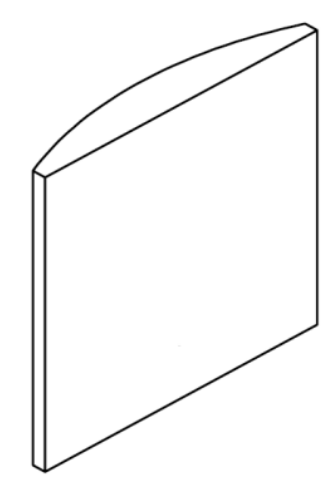

(a) isometric view

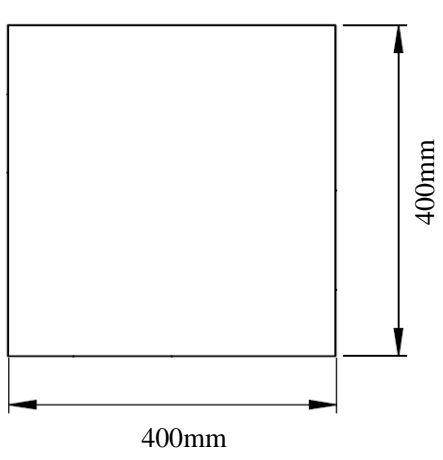

(b) side view

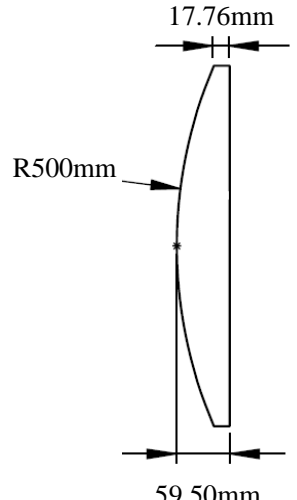

(c) plan view

Fig 5 Dimensions of the curved impact head
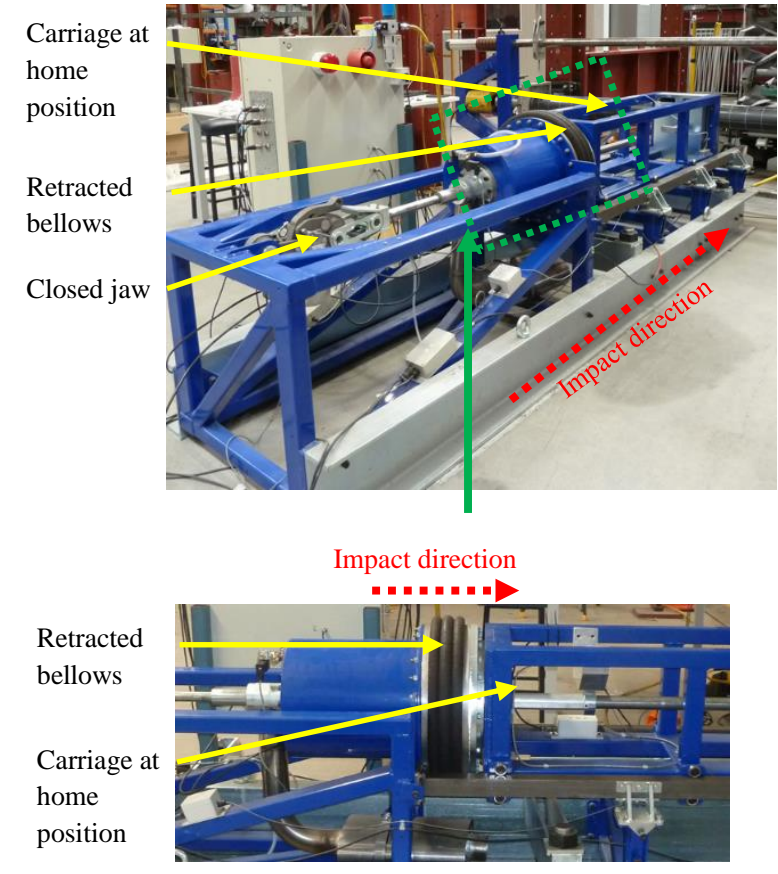

(a) before firing

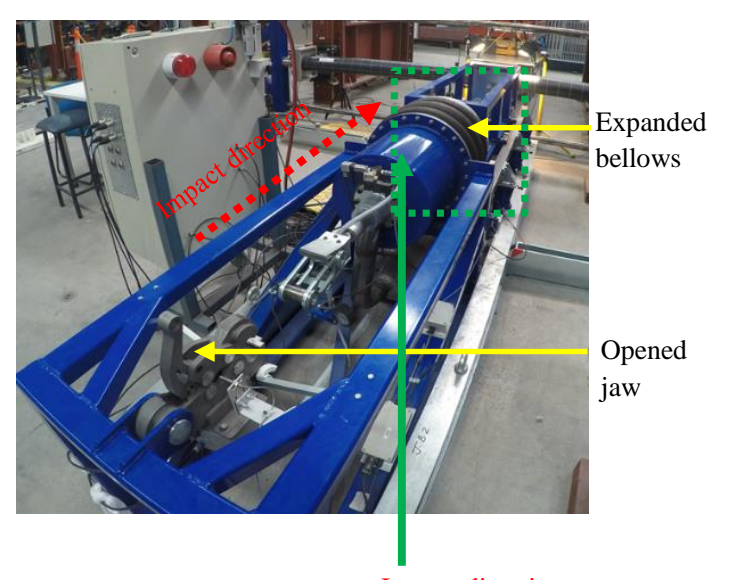

Impact direction

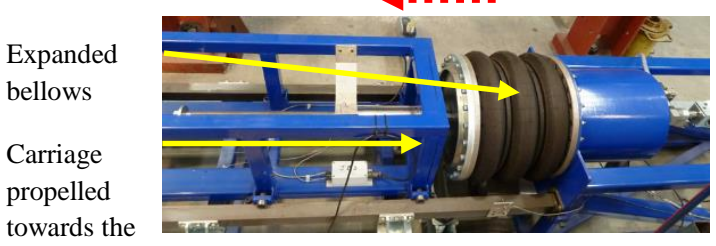

specimen

(b) after firing

Fig 6 Pneumatic instrumented striker before and after firing 


\section{Axial pre-loading frame}

The axial pre-loading frame (Fig 7) comprises of two specimen end caps, a ram cap at the hydraulic ram side, a plain cap or fixed support frame (depending on the required support conditions) at non-ram side, a set of selfreacting system of disc-springs and two tension-rods. When a fixed support is required at the non-ram side, the fixed support frame of the axial pre-loading frame can be coupled with the specimen support system to provide such condition. Since, in this study, simply supported conditions were considered at both specimen ends, the plain cap was used at the non-ram side and the ram cap was used at the ram side.

The axial pre-loading frame is suspended at each end through the top tension-rod by a steel hanger. This hanger is connected to a gantry via a gantry trolley. The gantry is constructed from a steel universal beam and bolted to a steel universal column that is fixed to the strong floor via a base plate.

Due to the very short impact duration, the hydraulic ram is unable to recover the loss in axial load caused by the columns' lateral deflection [19]. Therefore, a combination of tension-rods and a set of self-reacting compressive disc-springs are introduced into the axial loading frame to apply the axial load and effectively mitigate possible axial load loss. The employment of two parallel tension-rods and an appropriate stacking arrangement of discsprings on them, reduce the total number of disc-springs required and hence decrease the need for having relatively long stack of disc-springs as used by Zeinoddini et al. [18].

The two high tensile steel tension-rods are located on either side (i.e., top and bottom) of the specimen and passed through the ram cap at the ram side end and the plain cap at the other end (i.e., non-ram side). These rods are threaded at each end for a length of $500 \mathrm{~mm}$. A nut is inserted on the threaded section of each rod at each end and tightened in place. The disc-springs were stacked on the tension-rods between the ram cap and the nut at the ram cap side of the specimen. As shown in Fig $7 \mathrm{~b}$ and $7 \mathrm{c}$, upon travel of the plunger of the hydraulic ram towards the specimen, tensile and compressive forces are generated in the tension-rods and disc-springs, respectively. The tensioning of the rods and compression of disc-springs create a compressive axial load at both ends of the specimen, which is distributed across the specimen cross section by the specimen end cap. In this study, the annular disc-springs had an outer diameter of $125 \mathrm{~mm}$, an inner diameter of $67 \mathrm{~mm}$ and a thickness of $8 \mathrm{~mm}$. The springs were assembled in two different arrangements. The first arrangement used in the second and third series of tests had twelve sets of 2 parallel disc-springs in series (total of 24) while the second arrangement used in the fourth series of tests had six sets of 4 parallel disc-springs (total of 24) in each rod. A single stack of disc-springs 
in the first and second arrangements, as shown in Fig 8, can apply axial loads of more than $100 \mathrm{kN}$ and $200 \mathrm{kN}$, respectively, in the linear part of the disc-spring behaviour. The first and the second arrangements of these discsprings in the two parallel rods are hence capable of applying total axial loads of $200 \mathrm{kN}$ and $400 \mathrm{kN}$ required in the different tests series, in this study.

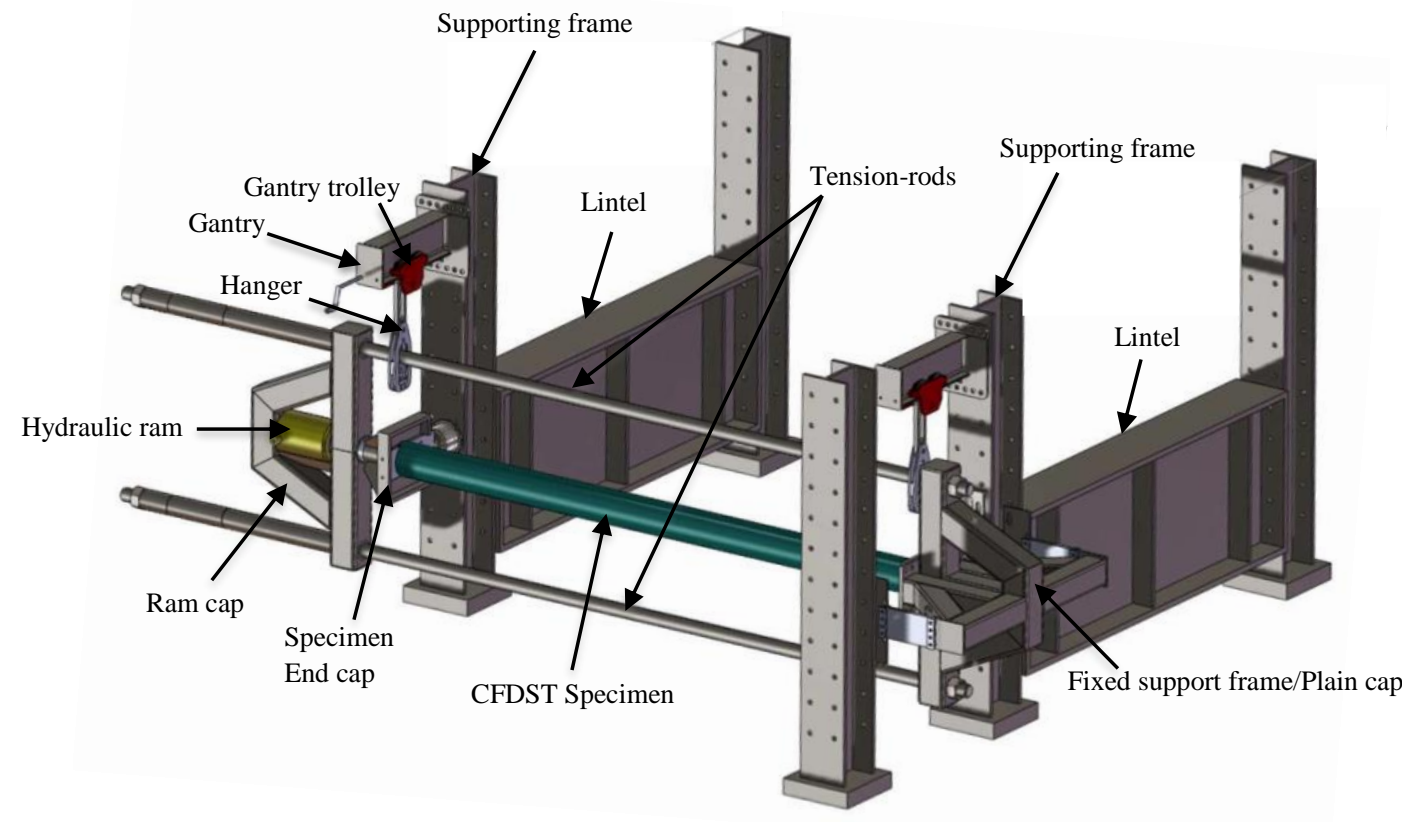

(a) Axial pre-loading frame

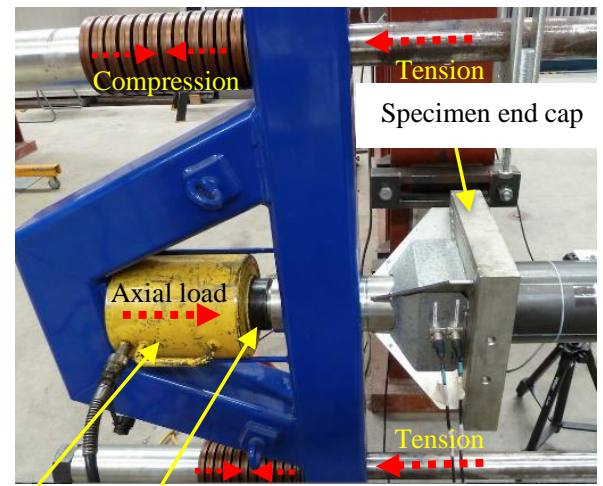

Hydraulic ram Plunger

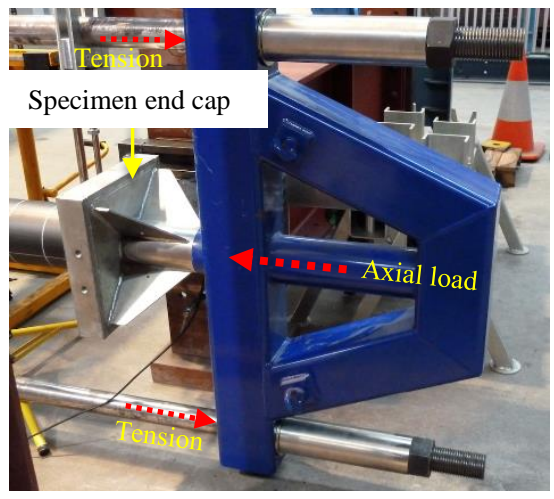

(c) Plain cap at non-ram side

(b) Ram cap at ram side

Fig 7 The axial pre-loading frame including specimen support system 


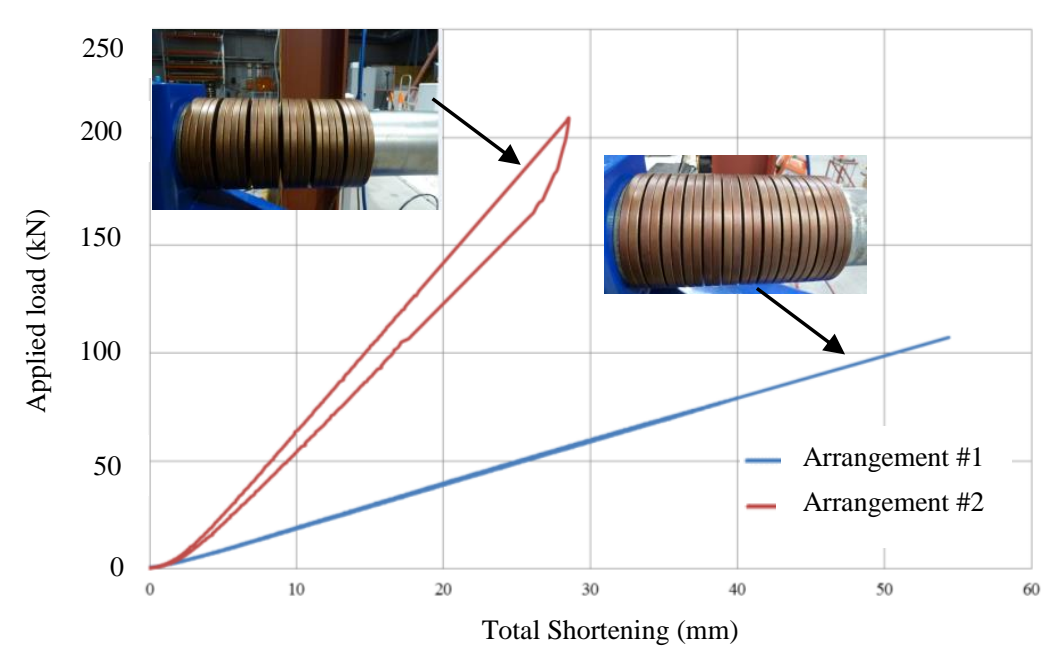

Fig 8 Different arrangements of single stack of disc-springs and their resulting characteristics

\section{Specimen support system}

The specimen support system comprises of a reaction plate and a supporting frame at each end of the specimen. A reaction plate (Fig 9) located at each specimen's end provides a support for the specimen in the direction that is parallel and opposite of the lateral impact force. The $10 \mathrm{~mm}$ thick steel reaction plate is welded at one end to the specimen end plate and clamped to the steel universal column at the other end. A steel frame (Fig 7a), located on either side of the specimen provides stability and stiffness in the direction of the impact. It comprises of two universal steel columns fixed to the strong floor and a steel lintel bolted to the columns at the impact height.

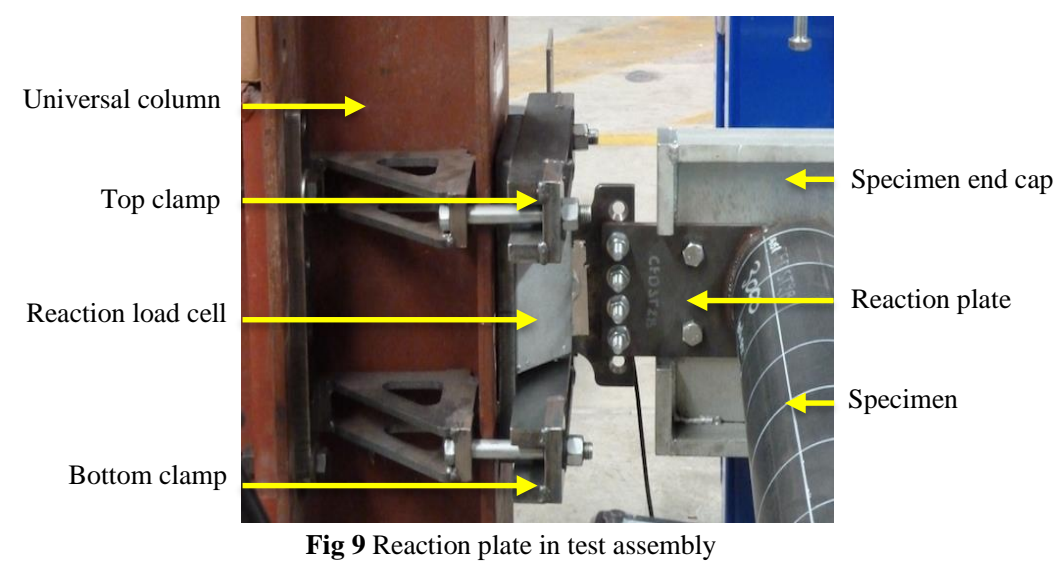

\section{Control box}

The control box houses the electronics required for the safe operation of the impact testing rig, as well as the data acquisition electronics. A high-speed data acquisition system was employed to digitise the output signals and to read, write and process the data. Sampling from all sensors was carried out simultaneously at a frequency of 25 
$\mathrm{kHz}$ per channel (i.e., the experimental data was recorded at every $40 \mu \mathrm{s}$ ) leading to a detailed reflection of the whole impact process.

\section{Data measuring instrumentation}

To measure the impact carriage velocity three different devices, namely a string potentiometer (Fig 10a), a velocity proximeter (Fig 10b) and two accelerometers (Fig 10b) were employed. Triangulating results obtained from these devices improve the confidence in the results and reduce the possibility of losing data altogether. The string potentiometer, Model Firstmark Controls 62-55-8442, which is a position transducer was used. Its housing was mounted to a beam on the impact end of the fixed frame of the striker, with the moving end of its string latched onto the rear of the carriage. From the recorded displacement-time history, the velocity profile of the carriage was obtained. The velocity proximeter consists of a proximity sensor (Model NBB0, 8-5GM25-E0) and steel linear tooth encoder rail. The encoder rail was mounted on the carriage and spans the entire length of the moving carriage. The proximity sensor was placed on the fixed section of the striker and faces the encoder rail vertically. When the impact carriage accelerates, the proximity sensor actively detects the presence of the steel teeth and changes the current. The changes in the current were output as binary signals. Knowing the tooth width, distance between the teeth and the rate of current change, the velocity of the carriage was determined. The accelerometers were housed in a protection box installed on the threaded rod at the centre of the back of the impact head. The integration of the carriage acceleration over time, provided the carriage velocity profile. Based upon the relative rigidity of the impact head in comparison with the CFDST columns, the obtained carriage acceleration from accelerometers along with known impact mass was also used to determine the impact force. A single axis accelerometer module, Model Silicon Designs 2260-200 with input range of $\pm 200 \mathrm{~g}$, was used in the first and second test series to measure the acceleration of the carriage during impact. However, during these tests, the accelerometer exceeded its measureable range due to vibration in the box frame of the impact carriage, which resulted in missing data. Therefore, in the rest of the tests, accelerometers with larger input ranges were used to overcome this issue. A $\pm 400 \mathrm{~g}$ single axis accelerometer module, Model Silicon Designs 2260-400, and a \pm 2000 g single axis accelerometer module, Model Meggitt 7264D, were employed in the third and fourth test series.

The analogue accelerometers were carefully mounted at a suitable location with a view to alleviating environmental noise; however, noise was still observed in their signals. This was mainly due to vibrations of the box frame of the impact carriage including all of the installed components. As the vibrations occurred at much higher frequencies than the acceleration of the impact carriage, it was relatively easy to filter out these effects by 
using a class of low pass finite impulse response (FIR) filter, which utilises the principle of moving average. An example of the unfiltered and filtered plots of the data obtained from the $2000 \mathrm{~g}$ accelerometer are presented in Fig 11, taken from test CFDST4A. It can be observed from Fig 11 that filtering greatly improved the acceleration signature. The larger spikes in the unfiltered acceleration data are consistently mirrored, indicating that they are not true measurements of the carriage acceleration. Rather, the mirroring of the acceleration data indicates that the accelerometer measures the vibrations of the carriage frame. In future studies, it will be preferable to reduce the amount of noise in the signals by designing a space within the body of impact head to accommodate the accelerometers. Using load cells can also provide a direct measurement of impact force.

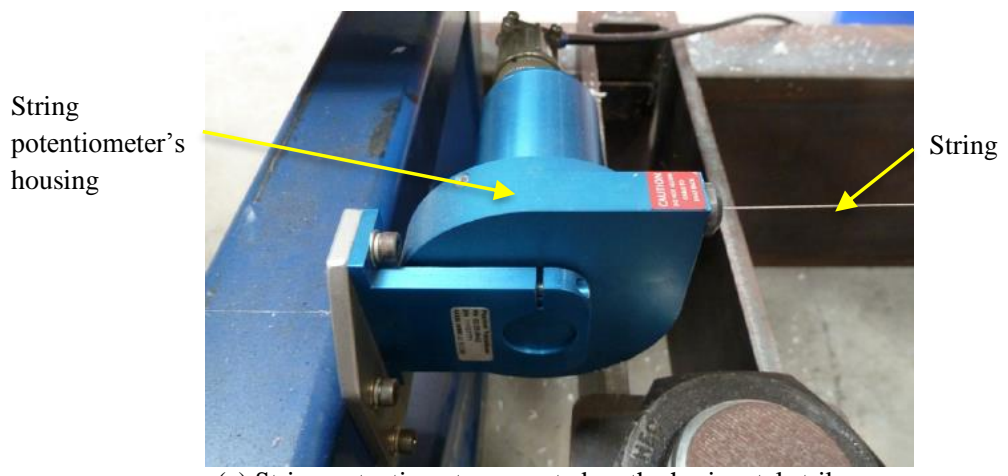

(a) String potentiometer mounted on the horizontal striker

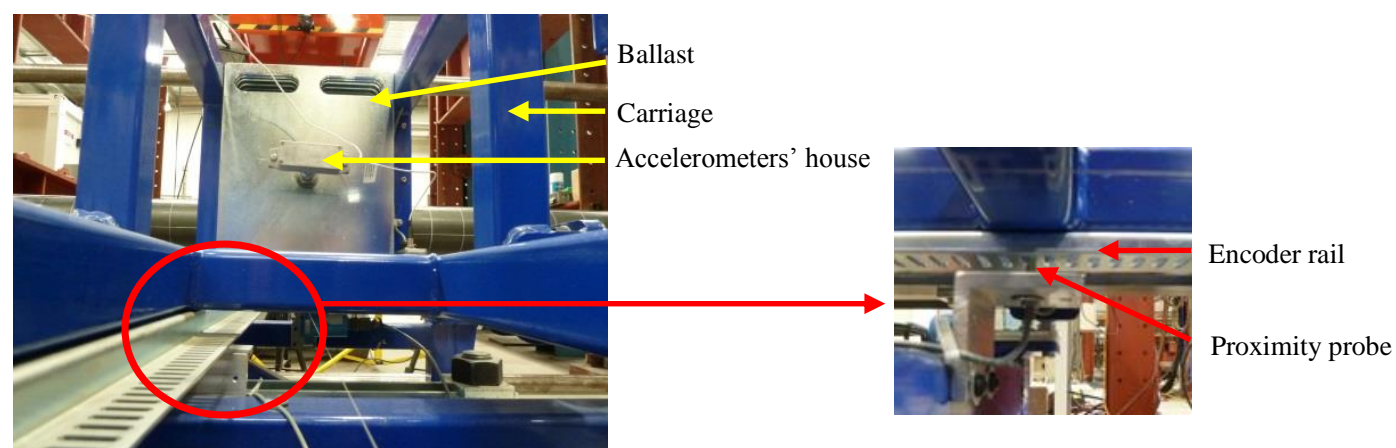

(b) Velocity proximeter and accelerometers housed on the impact carriage

Fig 10 Devises used to measure velocity of carriage

The data acquired from the analogue string potentiometer also contained some high-frequency noise. This noise was also attributed to the mechanical vibration of the carriage. Therefore, a moving average was used to treat these signals. 


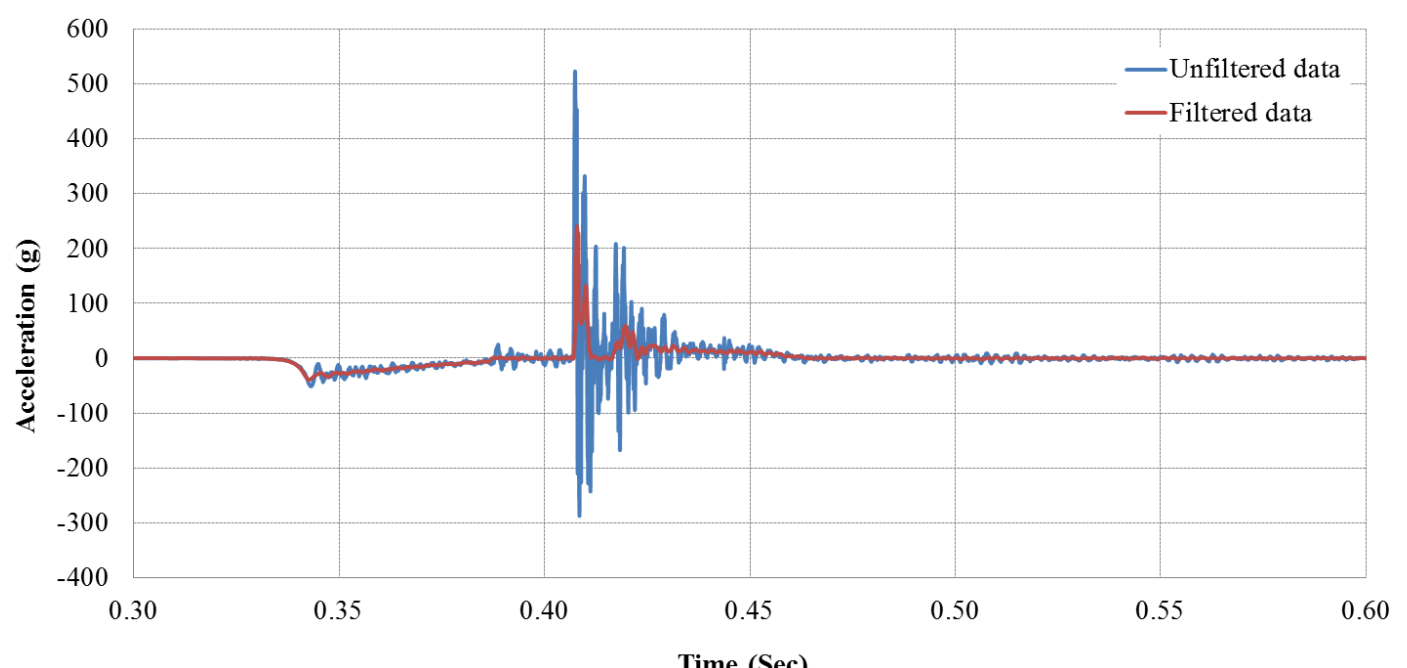

Fig 11 Unfiltered and filtered accelerometer data from test CFDST4A

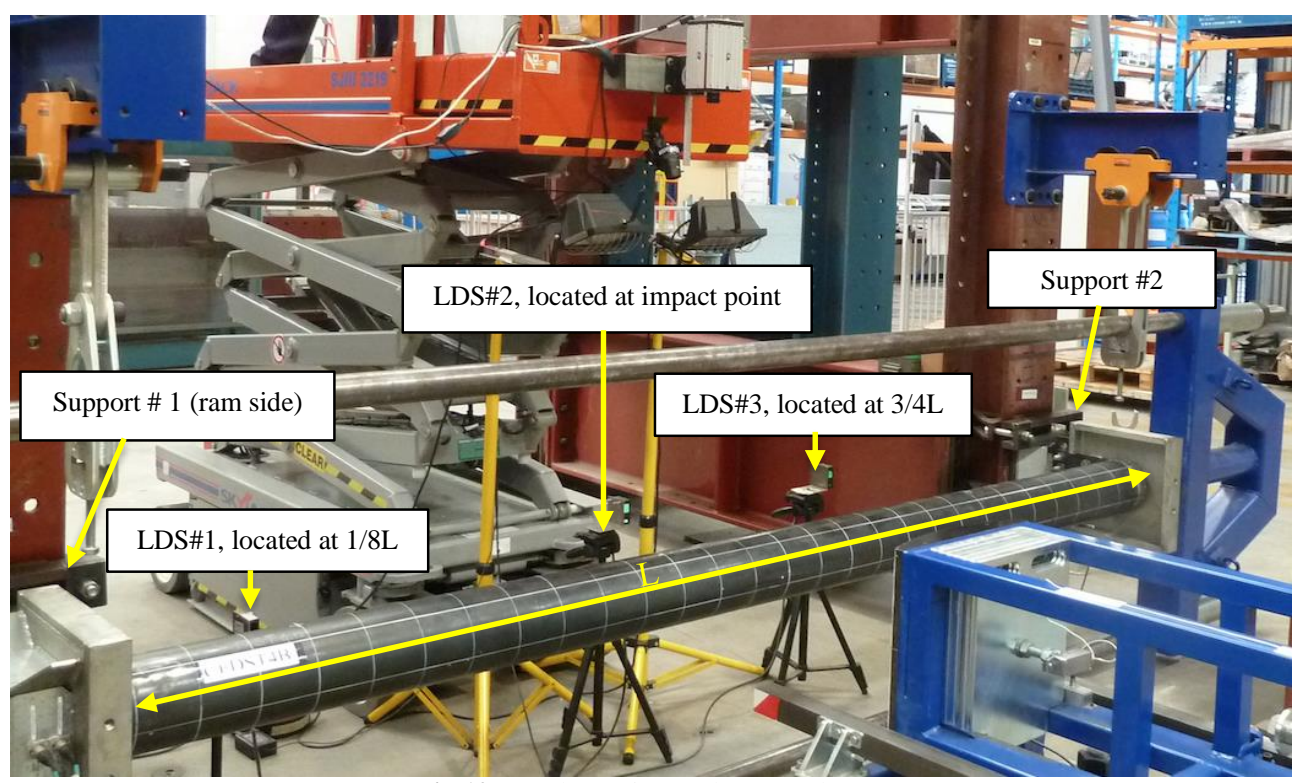

Fig 12 Locations of LDSs in test series \#4

To monitor the axial load during the impact, two calibrated $1500 \mathrm{kN}$ axial load cells were housed on the specimen end cap located on the ram cap side of the loading frame. Additionally, a compression-tension load cell with the measuring range of $\pm 450 \mathrm{kN}$ was placed at either side of the specimen between the reaction plate and the universal column of specimen support system (Fig 9) to record the reaction forces.

A high-speed camera was employed to closely monitor the behaviour of the column at the impact zone. The camera was X-Stream ${ }^{\mathrm{TM}}$ XS-4, which is a high-speed video recording system capable of recording 5145 frames $/ \mathrm{sec}$ at full resolution of $512 \mathrm{H} \times 512 \mathrm{~V}$ pixels. The camera was equipped with the Computer $8 \mathrm{~mm}$ F1.4 MO814-MP lens to capture the dynamics of the event. This camera was mounted $1030 \mathrm{~mm}$ above the specimen and was able to deliver a good view of about $1000 \mathrm{~mm}$ of the length of the specimen at impact zone. The sample rate was set to $1600 \mathrm{~Hz}$. 
Two laser displacement sensors (LDSs), Model ZX1-LD300A61, with measuring range of 300 $\pm 150 \mathrm{~mm}$ and resolution of $30 \mu \mathrm{m}$ and one LDS, Model 1402-50, with measuring range of $50 \pm 25 \mathrm{~mm}$ and resolution of $5 \mu \mathrm{m}$ were used to measure the global deflection and provide an indication of the column curvature. In all tests, one of the LDSs with the measuring range of $300 \pm 150 \mathrm{~mm}$ was used at back of the column (i.e., non-impact side) at the impact point. The other LDS with the same measuring range was used at column mid-span in the third series of tests, and at three fourth of column length away from support \#1 (location of the support \#1 is shown in Fig 12) in the rests of the tests. The LDS with measuring range of $50 \pm 25 \mathrm{~mm}$ was used at one fourth of column length away from support \#1 in the first test and at one eighth of column length away from Support \#1 in rest of the tests. The location of LDSs was chosen for each test based on the space constraints in the tests and LDS's measuring limit. Locations of LDSs in the fourth series are shown in Fig 12.

\section{Test procedure}

The axial load was gradually increased until it reached the specified value. The actuator was then charged with compressed air to the desired level using the LabView application on the computer. Once the specified pressure was reached, the impact carriage, aimed already towards the desired point on the specimen, was lunched. Movement of the carriage from the firing position was detected by a proximity sensor, which triggered all the sensors including high-speed camera.

\section{Experimental Results and Discussion}

Fig 13 shows an example of the comparison of the carriage velocity profiles calculated from $2000 \mathrm{~g}$ accelerometer, the string potentiometer and the proximity sensor in CFDST4A test. In general, a good correlation was found among the results from the different measurement methods. Additionally, Fig 14 shows a comparison of impact force-time histories obtained from the $400 \mathrm{~g}$ and $2000 \mathrm{~g}$ accelerometers. In general, there was a good agreement in the results from the two accelerometers.

Fig 15, Fig 16 and Fig 17 present the results for time-histories of the impact force, reaction force and global deflection, respectively. Additionally, Table 3 contains a summary of the key experimental results. In this table, $\delta_{m}$ is maximum deflection, $\delta_{r}$ is residual deflection, $F_{m}$ is initial peak force, $t_{i}$ is the impact duration, $R_{m t}$ and $R_{m c}$ are initial peak total reaction forces in tension and compression, respectively, $t_{r}$ is the reaction force duration, $L_{b}$ is the length of local buckling and $W_{b}$ and $D_{b}$ are the width and depth of local buckling, respectively. Due to 
overloading of the $\pm 200 \mathrm{~g}$ accelerometer, the impact force-time histories in the first and second test series were missed.

For specimens with the same axial load and impact location, the test results confirmed the repeatability of the measured impact response. It is evident that the level of the axial load and impact location have noticeable effects on lateral impact response of the column. Since repeatability of tests with the same parameter combination has been confirmed, the rest of the discussion will treat the results of the specimens CFDST1A, CFDST2C, CFDST3B and CFDST4B as representative of test series \#1, test series \#2, test series\#3 and test series \#4, respectively.

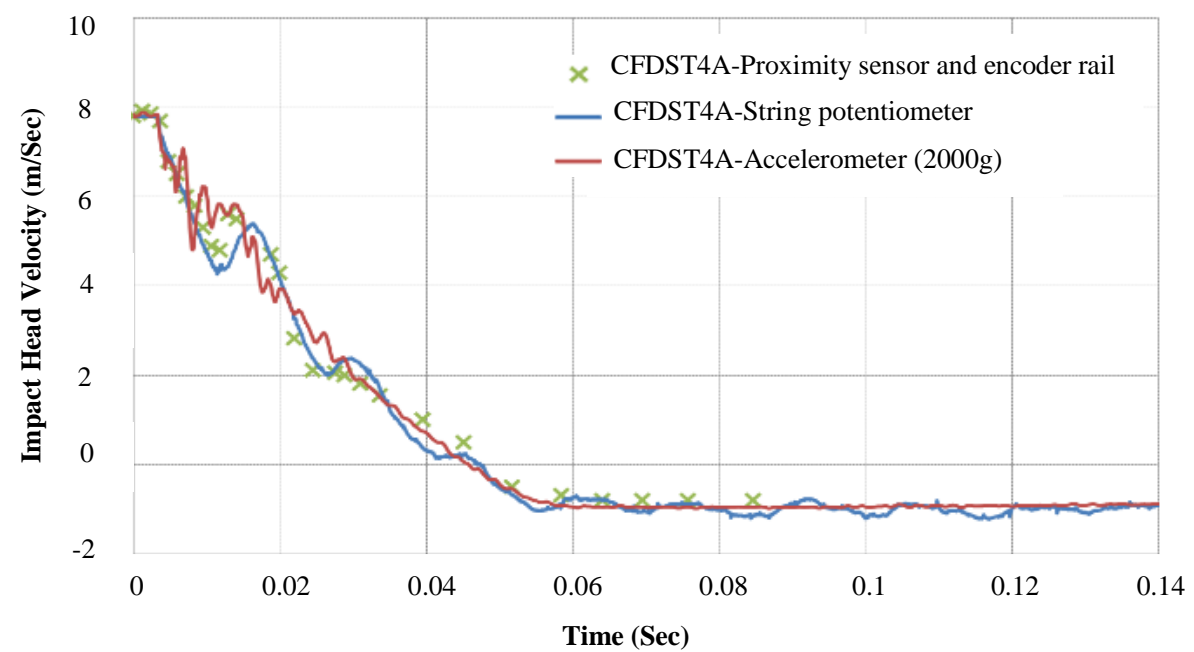

Fig 13 Carriage velocity-time history obtained in CFDST4A test from proximity sensor, string potentiometer and $2000 \mathrm{~g}$ accelerometer

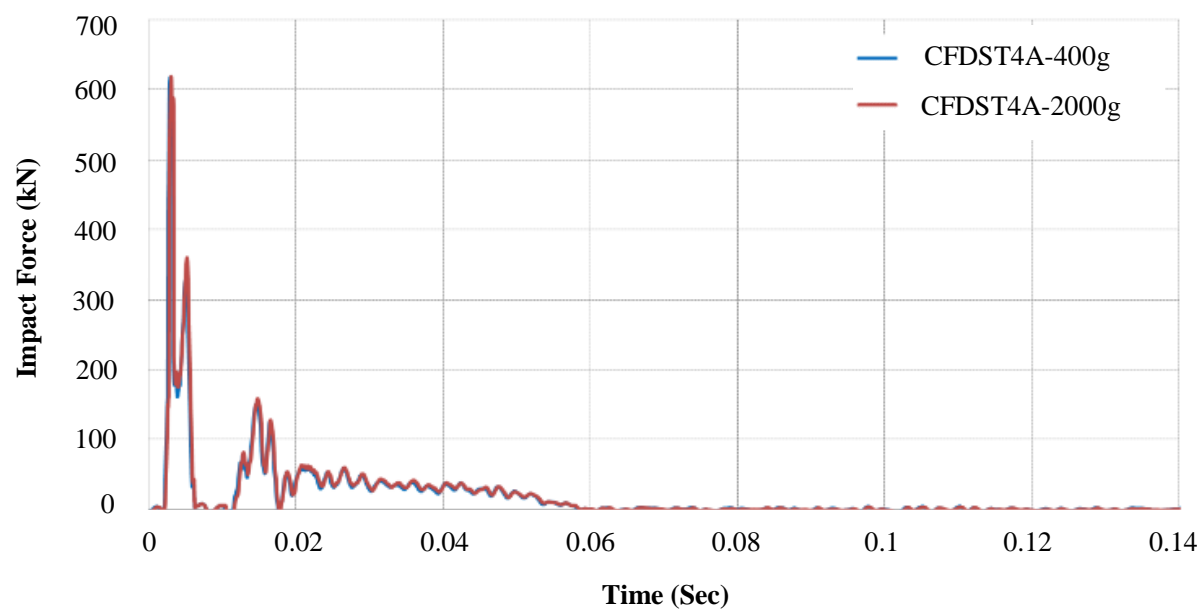

Fig 14 Comparison of impact-time histories obtained based of acceleration results of $400 \mathrm{~g}$ and $2000 \mathrm{~g}$ accelerometers in CFDST4A test 


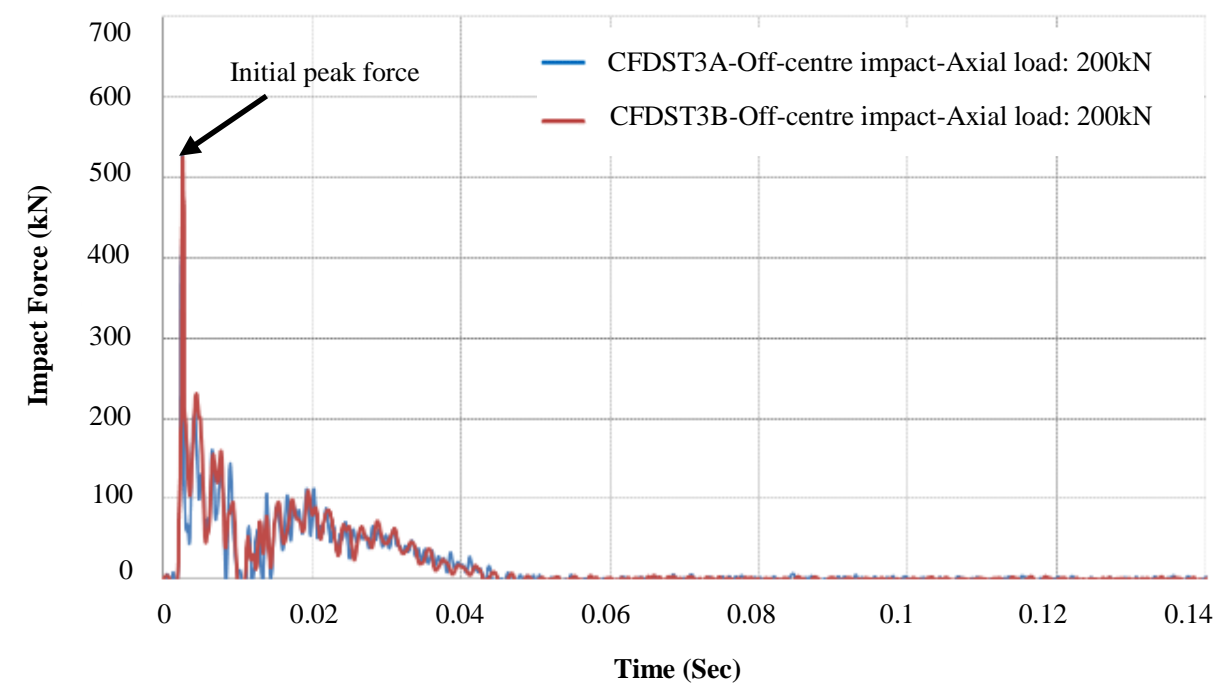

(a) Test series \#3

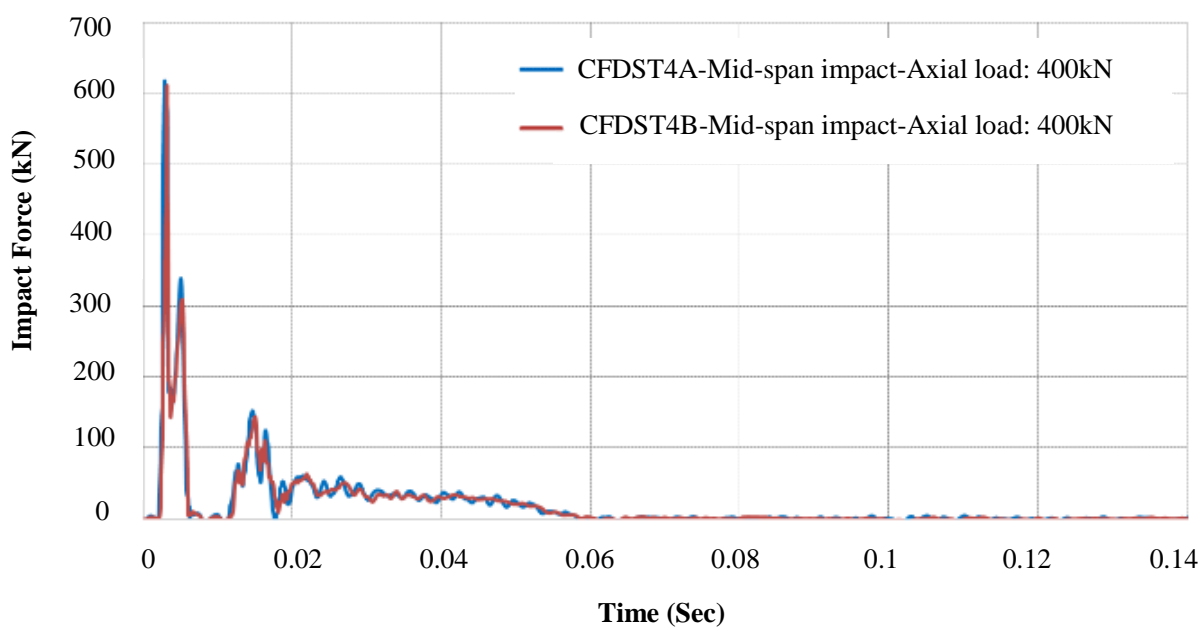

(b) Test series \#4

Fig 15 Impact force-time histories obtained in the tests

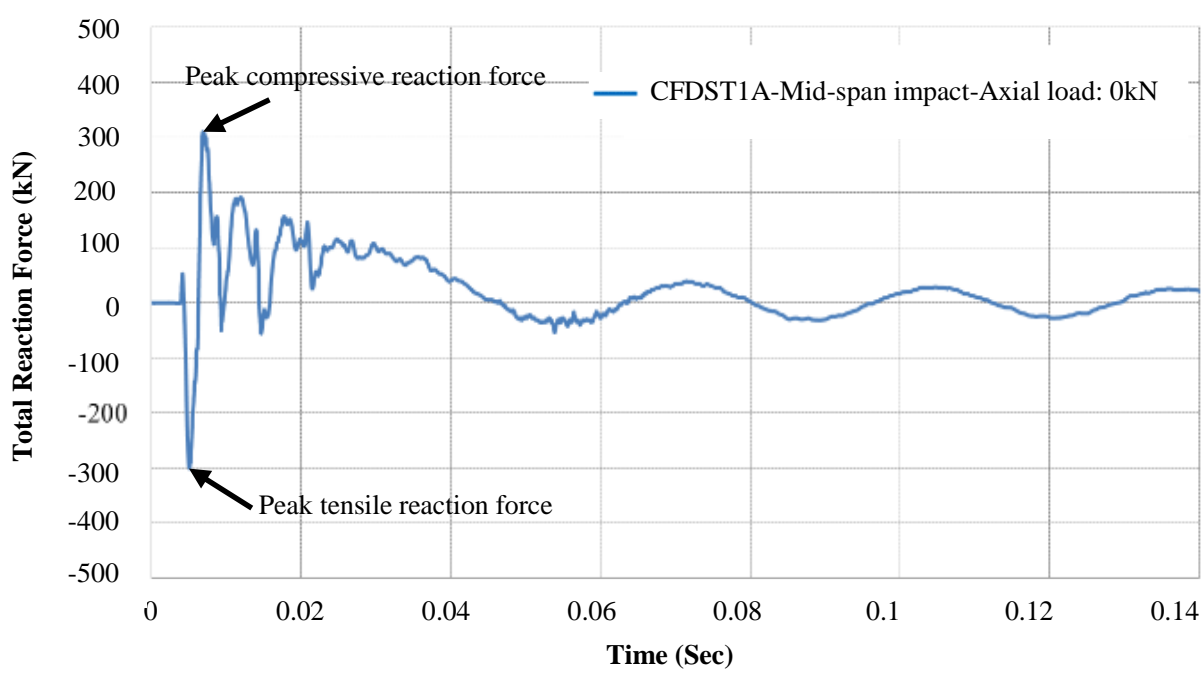

(a) Test series \#1 


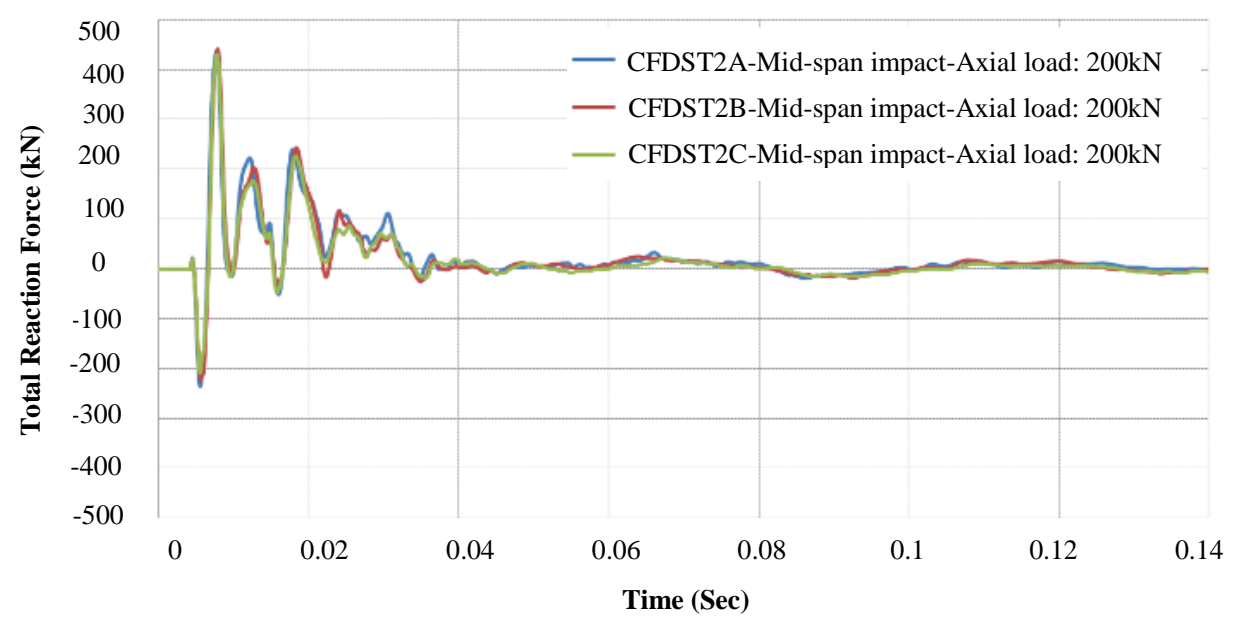

(b) Test series \#2

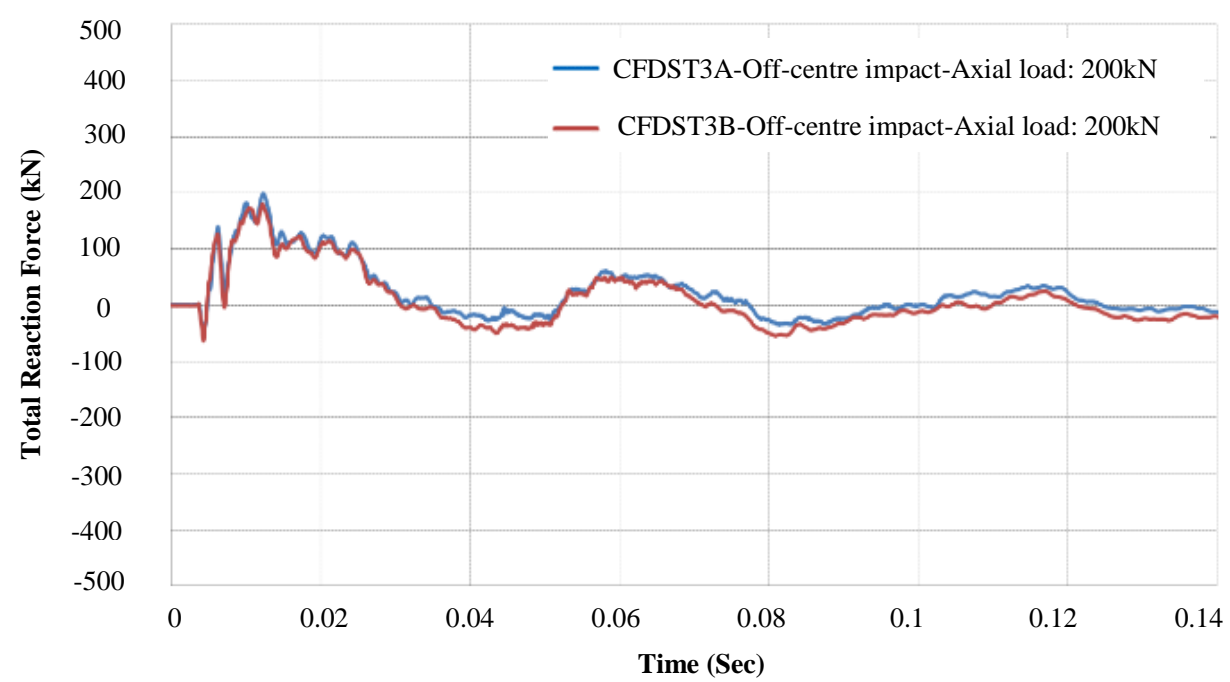

(c) Test series \#3

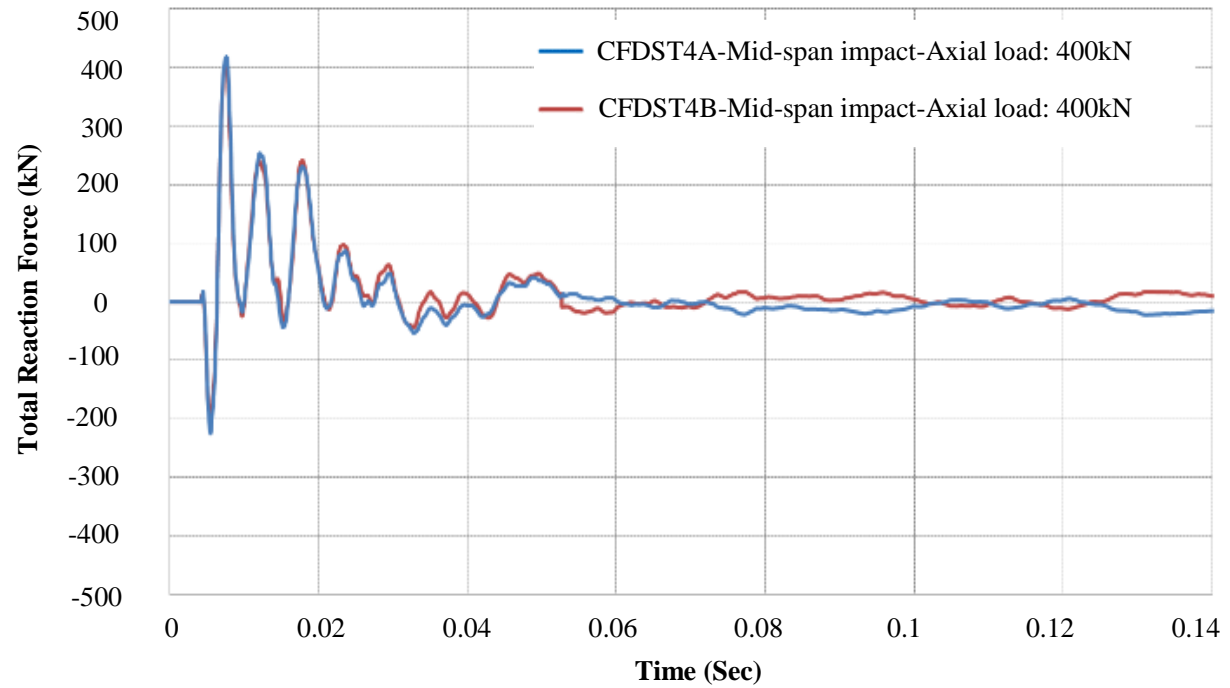

(d) Test series \#4

Fig 16 Total reaction force-time histories obtained in the tests 


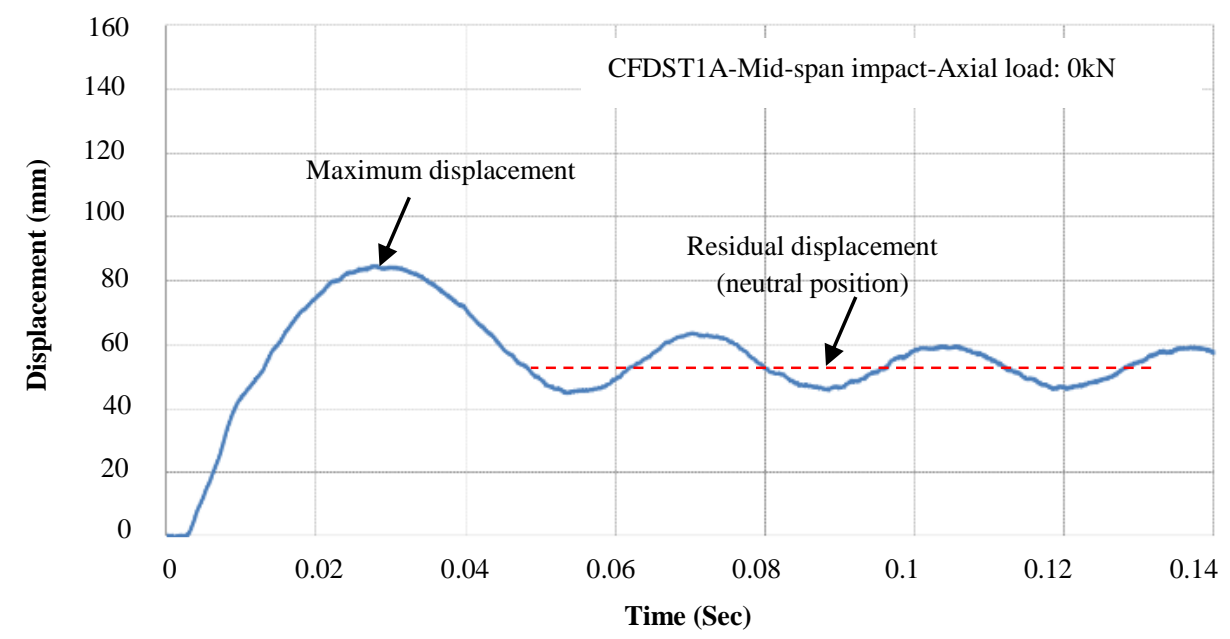

(a) Test series \#1

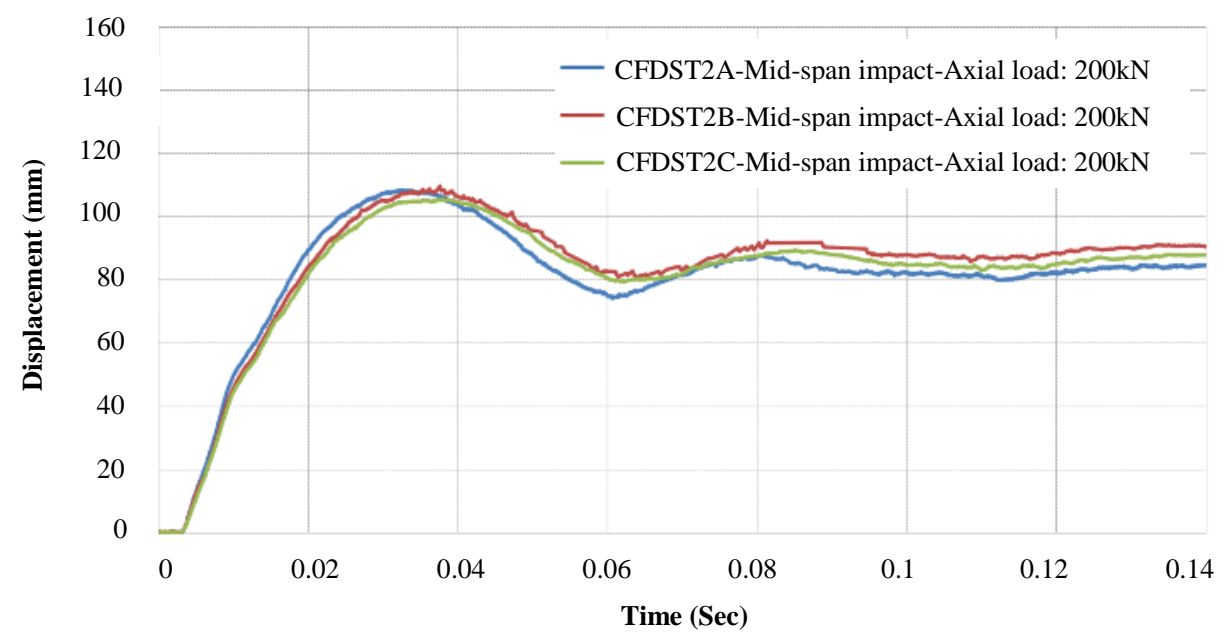

(b) Test series \#2

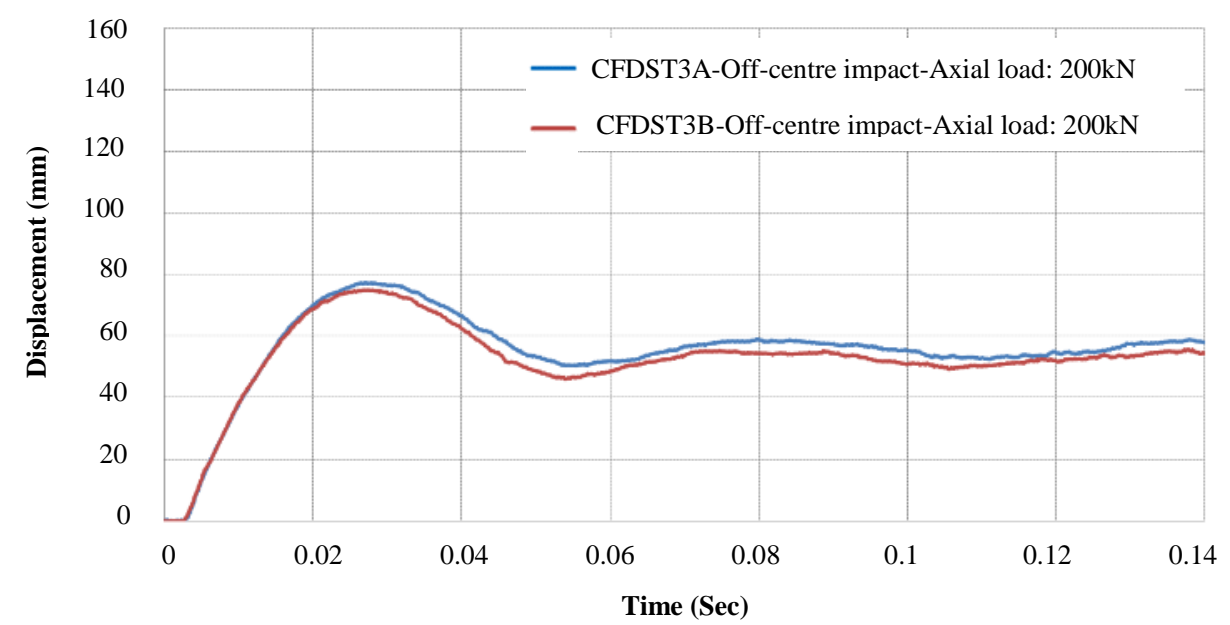

(c) Test series \#3 


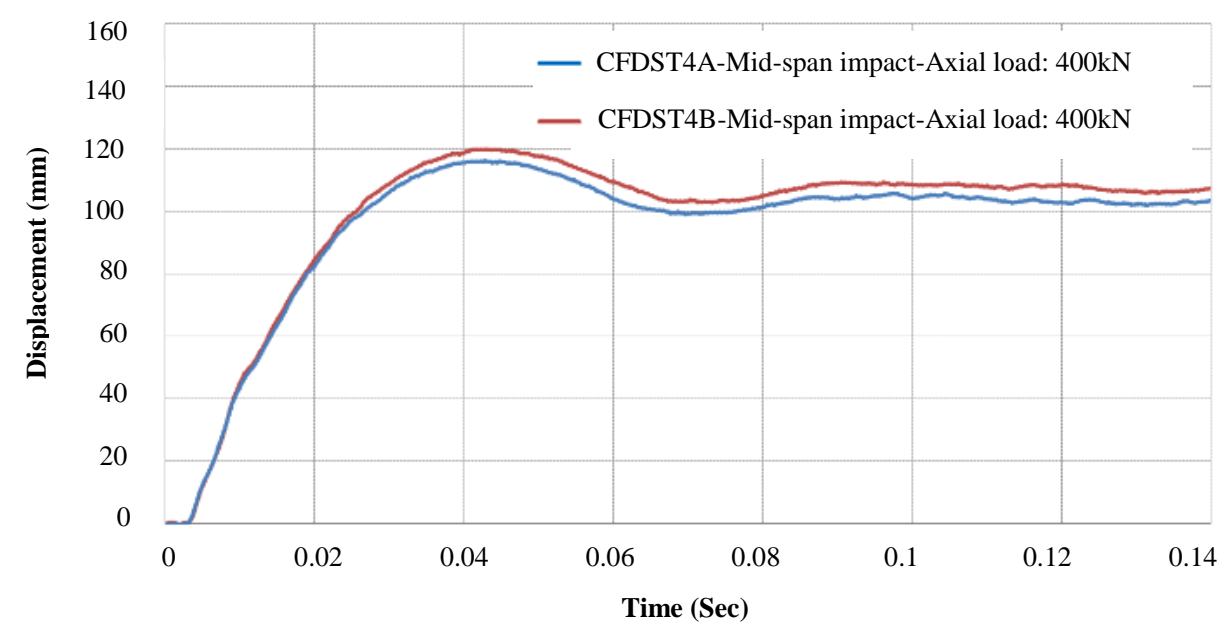

(d) Test series \#4

Fig 17 Global displacement-time histories obtained in the tests

Table 3 Summary of the experimental results

\begin{tabular}{|l|c|c|c|c|c|c|c|c|}
\cline { 2 - 10 } \multicolumn{1}{c|}{} & CFDST1A & CFDST2A & CFDST2B & CFDST2C & CFDST3A & CFDST3B & CFDST4A & CFDST4B \\
\hline $\boldsymbol{\delta}_{\boldsymbol{m}}(\boldsymbol{m m})$ & 84.8 & 108.6 & 109.8 & 105.7 & 77.3 & 75.0 & 120.0 & 116.4 \\
\hline $\boldsymbol{\delta}_{\boldsymbol{r}}(\boldsymbol{m m})$ & 53 & 82 & 89 & 86 & 54 & 51 & 107 & 103 \\
\hline $\mathbf{F}_{\mathbf{m}}(\boldsymbol{k N})$ & N/A & N/A & N/A & N/A & 529.5 & 526.1 & 618.1 & 611.4 \\
\hline $\mathbf{t}_{\mathbf{i}}(\boldsymbol{m} \boldsymbol{s})$ & N/A & N/A & N/A & N/A & 42.2 & 42.3 & 56.3 & 57.5 \\
\hline $\mathbf{R}_{\mathbf{m t}}(\boldsymbol{k N})$ & -300.1 & -236.1 & -224.2 & -209.1 & -55.1 & -63.1 & -200.6 & -224.8 \\
\hline $\mathbf{R}_{\mathbf{m c}}(\boldsymbol{k} \boldsymbol{N})$ & 310.3 & 438.3 & 441.6 & 430.4 & 199.6 & 180.8 & 410.9 & 417.6 \\
\hline $\mathbf{t}_{\mathbf{r}}(\boldsymbol{m} \boldsymbol{s})$ & 43.6 & 31.0 & 32.9 & 32.0 & 29.2 & 28.9 & 26.1 & 27.1 \\
\hline $\mathbf{L}_{\mathbf{b}}(\boldsymbol{m m})$ & 85.0 & 90.4 & 96.0 & 93.0 & 90.5 & 89.0 & 100.0 & 99.0 \\
\hline $\mathbf{W}_{\mathbf{b}}(\boldsymbol{m m})$ & 26.4 & 28.6 & 30.0 & 27 & 30.0 & 30.0 & 29 & 30.0 \\
\hline $\mathbf{D}_{\mathbf{b}}(\mathbf{m m})$ & 2.10 & 2.7 & 2.8 & 2.8 & 2.1 & 2.1 & 2.9 & 2.7 \\
\hline
\end{tabular}

Failure mechanism

Fig 18 shows the CFDST columns after the impact and it is evident that all the specimens experienced global bending deformation failure. The increase in the axial load level increased the column global buckling due to exacerbation of second-order bending effect. In addition to the global failure, local bucking was observed in all specimens at the point of impact. Fig 19 shows a typical local buckling of the columns. 


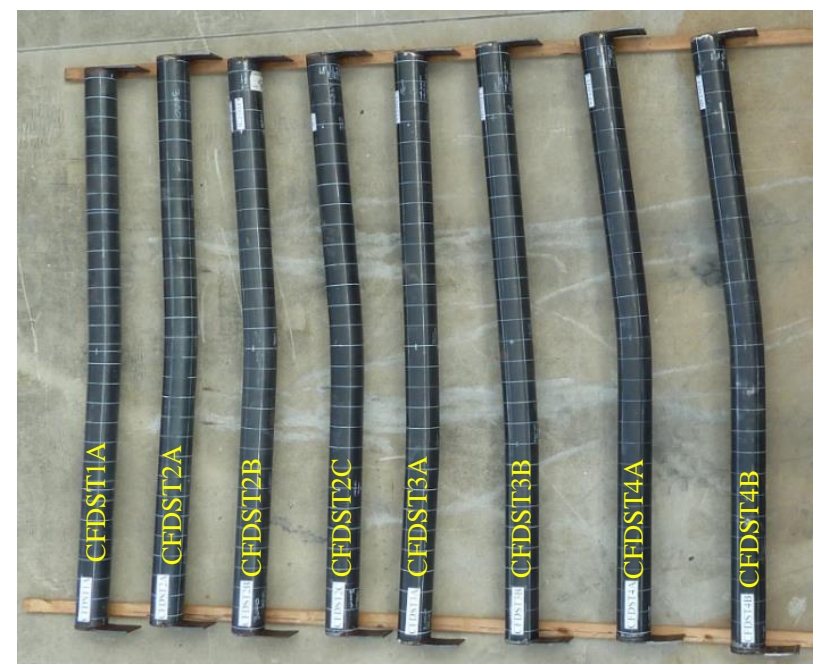

Fig 18 Global buckling of CFDST columns observed in the impact tests

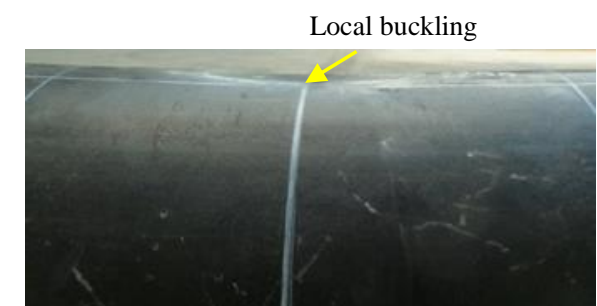

Fig 19 Typical local buckling failure of CFDST columns observed in the impact tests

In order to assess the concrete core and inner tube condition after the tests, initially $500 \mathrm{~mm}$ of outer steel tube at each side of the impact point (i.e., total cut length=1000 mm) was removed by an angle grinder with metallic blade and then the $1000 \mathrm{~mm}$ exposed concrete was detached from the steel inner tube using an angle grinder with diamond blade. Fig 20 and Fig 21 demonstrate the failure modes of the concrete and the inner tubes, respectively. It can be seen that in all tests concrete dented at the impact point where the column local buckling occurred. The geometrical characteristics and shape of the dent was analogous to those of the local buckling of the column. In addition to concrete dent, concrete cracks, formed around the impact zones at the impact side and its counterpoint (i.e., non-impact side), can be observed in all the tests. The cracks are wider at the impact side compared to the impact counterpoint, generally. The presence of axial load increased the propagation length and width of the cracks. Shifting the impact location from mid-span towards the support resulted in formation of wider cracks at closer distance to the impact point, at impact side. In general, the integrity of concrete was fairly good in view owing to the effective confinement provided by outer and inner steel tubes. As seen from Fig 21, the inner tubes experienced global buckling and there was no evidence of local bucking. 

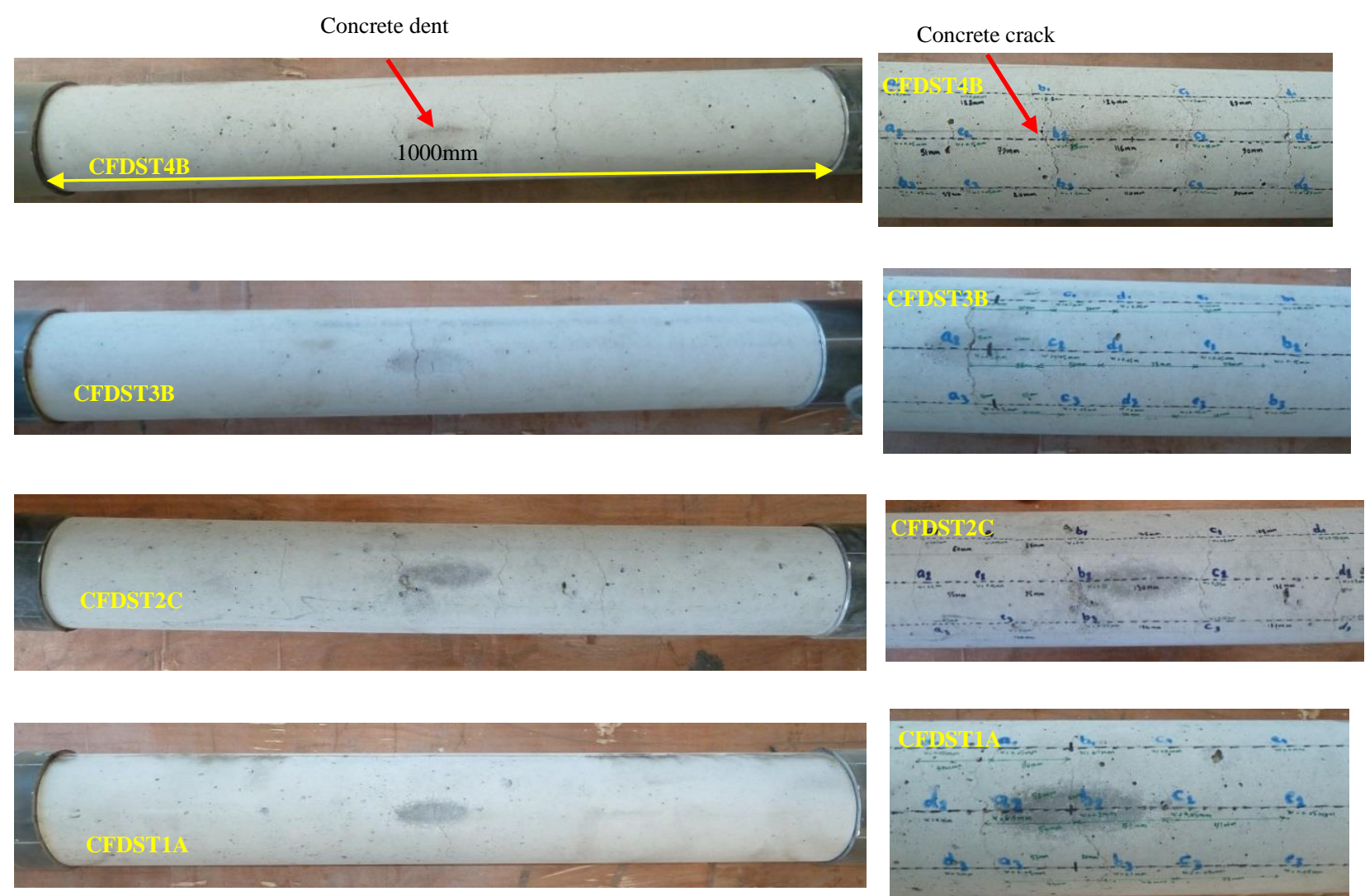

(a) Broad view

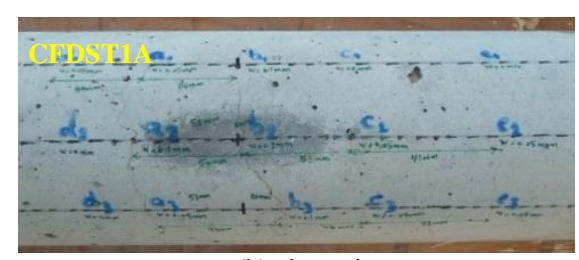

(b) close view

Fig 20 Failure mode of concrete core at the impact side
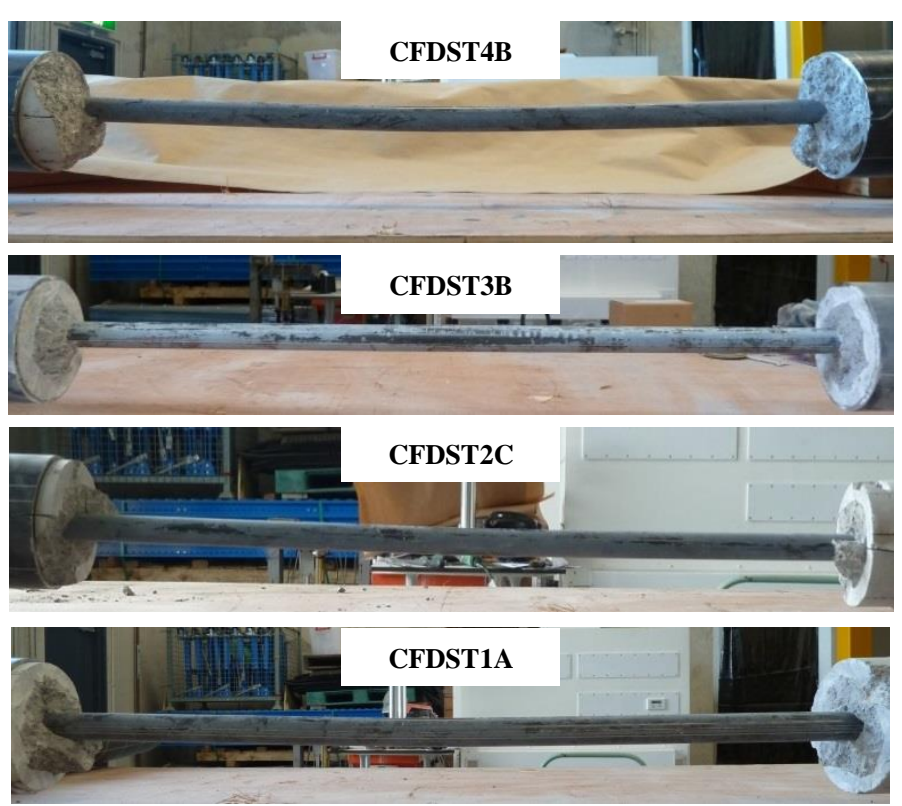

Fig 21 Global buckling of inner steel tubes

\section{Impact force-time histories}

Fig 22 shows the impact force-time histories for the third and fourth test series. The impact force increases sharply to a peak value at the very beginning of the strike as the specimen accelerates from a zero velocity to a velocity 
approaching that of the impact head. This force causes severe vibrations of the specimen and the striker, leading to fast changes of the contact area between the specimen and the impact head, reflected as fluctuations in the impact force-time history. In some cases, loss of contact between the specimen and the impact head for very short duration(s) (seen as zero impact force) was also observed. Similar vibration phase was reported in studies conducted by Han et al. [23] and Wang et al. [6] on steel-concrete composite members subjected to lateral impact by a steel rigid indenter. As single impulse would be ideal for studies such as the one treated here, it is proposed that response damper be designed in the HITS for future investigations.

After the vibration phase, the specimen and the impact head move together and remain in contact, as observed by the high-speed camera (Fig 23). During this phase, the impact force reaches a plateau. As soon as the specimen reaches its maximum global displacement, the specimen and the impact head rebound. This would be the end of the plateau phase and the start of the unloading phase. In the unloading phase, the impact head rebounds at a faster velocity than the specimen, the bending stiffness of which slows down the rebound. This results in a contact loss and unloading of the impact force to zero value. As depicted in Fig 22, the impact force-time history as well as the impact process consist of four main phases: initial peak phase, vibration phase, plateau phase and unloading phase.

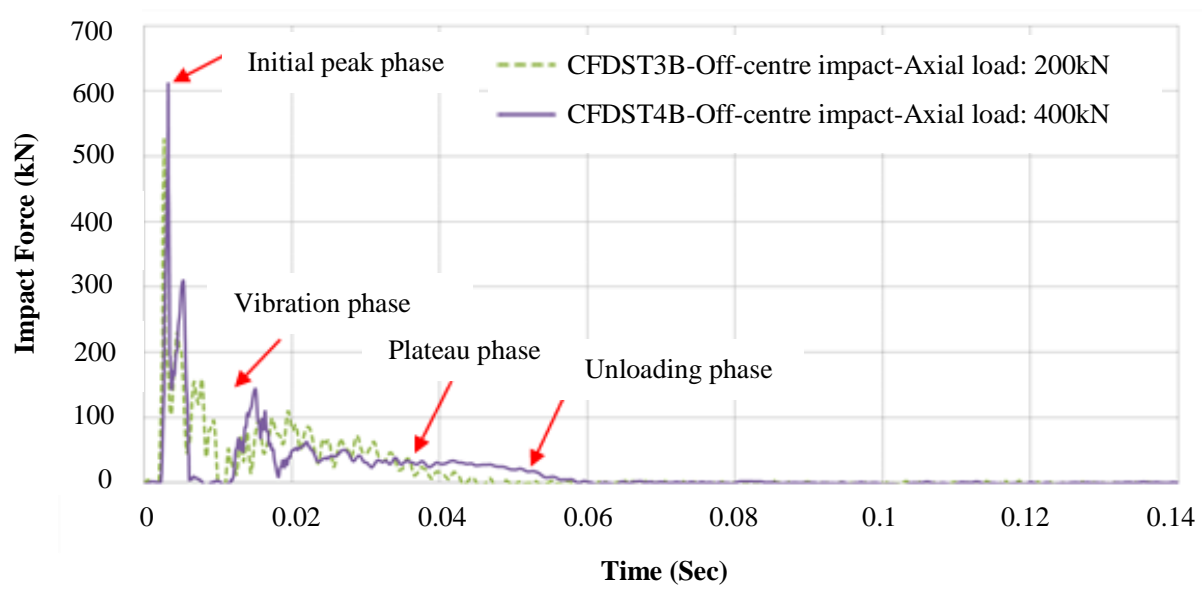

Fig 22 Impact force-time history for test series\#3 and test series\#4 


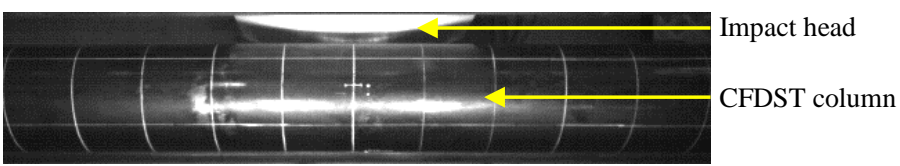

$\mathrm{t}=0$ ms (before impact)

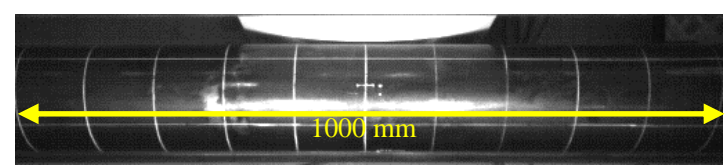

$\mathrm{t}=3.08 \mathrm{~ms}$ (time of start of impact)

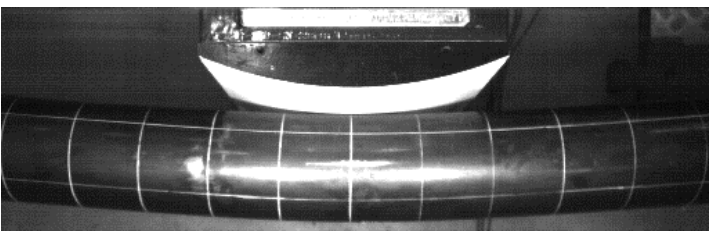

$\mathrm{t}=43.71 \mathrm{~ms}$ (time of maximum global deflection)

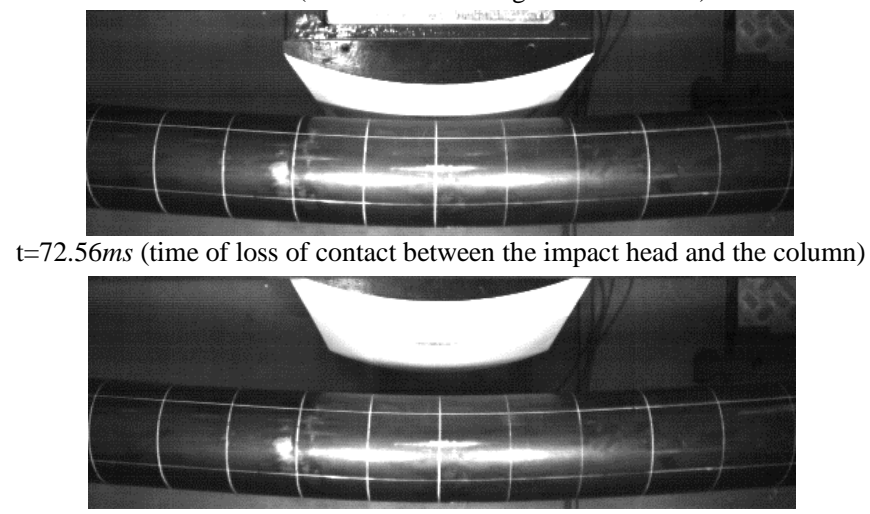

$\mathrm{t}=140 \mathrm{~ms}$ (end time of impact event)

Fig 23 Selection of frames taken from the high-speed camera for the impact test on CFDST4B

\section{Reaction force-time histories}

The total reaction force recorded during the tests for specimens under different levels of axial loads and impacted at different locations are compared in Fig 24.

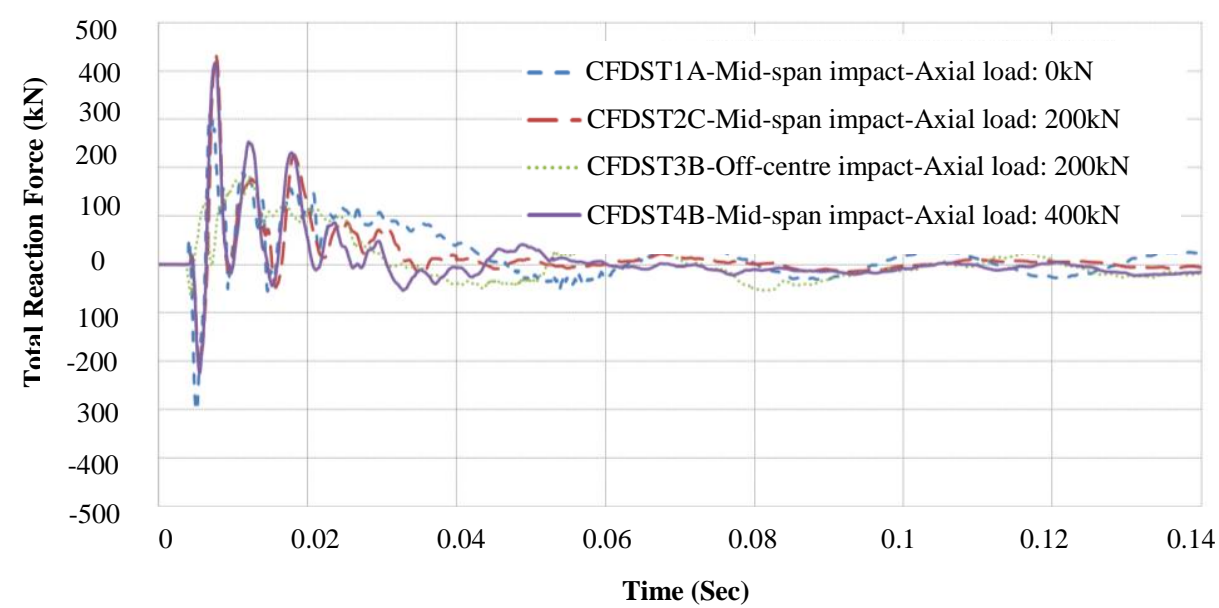

Fig 24 Reaction force-time history for test series\#1, test series\#2, test series\#3, test series\#4 
From this Figure and Fig 22, it is evident that there is a time lag between the start of reaction force and impact force. This is due to the time taken for the stress waves to travel from the impact point to the supports. The reaction force changes direction throughout an impact event. As soon as the impact force wave reaches the supports, the reaction force sharply increases to a peak value (i.e., initial peak tensile force) in the direction of the applied impact force, which is opposite to the situation under static force. High acceleration of the column in this phase gives rise to the inertial force, causing the inertial force to be larger than the applied impact force. Consequently, the true bending force is in same direction of the inertial force and the total reaction force is in the same direction of the impact force. As soon as the impact force wave associated with the vibration phase arrives, the reaction force changes its direction and reaches another peak value in the opposite direction (i.e., initial peak compressive force), which is then followed by other spikes of smaller amplitude. The change in the direction of the force from negative to positive could be due to reduction of the inertial effects caused by the column deceleration. After this phase, as in the impact force-time history, the total reaction force reaches a plateau followed by a gradually decreasing phase until it approaches zero. Fig 24 shows that the presence of axial load results in a reduction in the initial peak tensile force as well and the duration of the total reaction force, while it causes an increase in the initial peak compressive force. Shifting the impact location from the mid-span towards one of the supports reduces the peak forces as well as the total reaction force duration.

\section{Global displacement-time histories}

Fig 25 shows the global displacement-time histories of the specimens in the different test series. Comparing with Fig 22, this figure reflects a time lag between the start of impact force and the deflection at impact point. The lag could be associated with the inertia effect. In all the tests, the global displacement gradually increases to its peak value and then decreases with the rebound of the specimen. After the separation of the specimen and the impact head, the specimen recovers the elastic portion of the deflection and then begins to vibrate freely until the energy is damped out. This vibration leads to the slight oscillation of the displacement curve. 


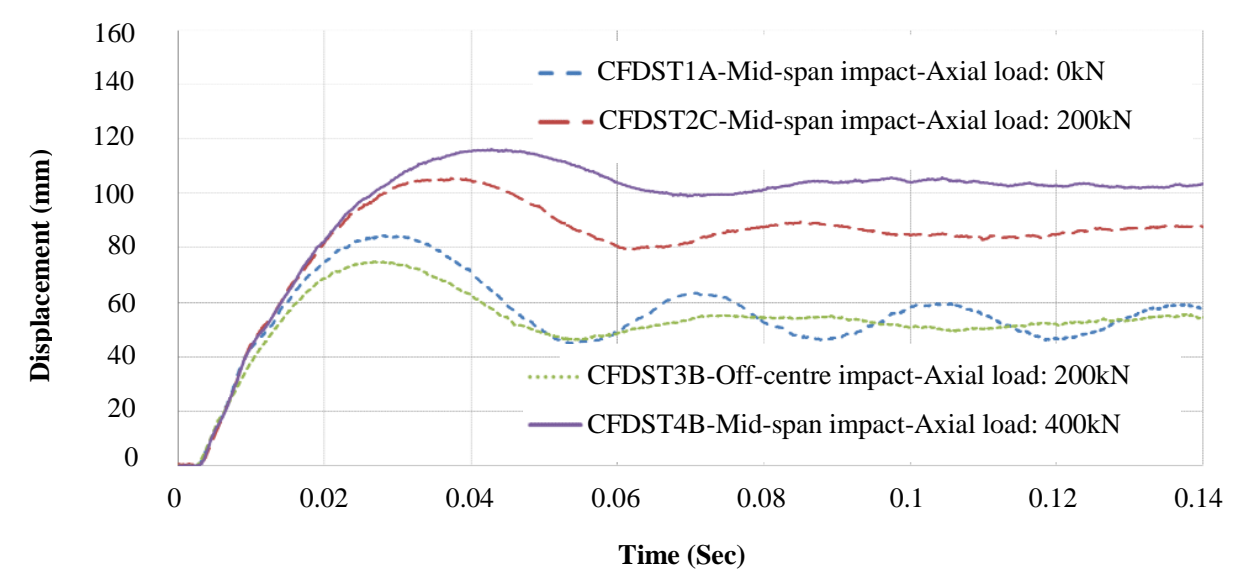

Fig 25 Global displacement-time history for test series\#1, test series\#2, test series\#3, test series\#4

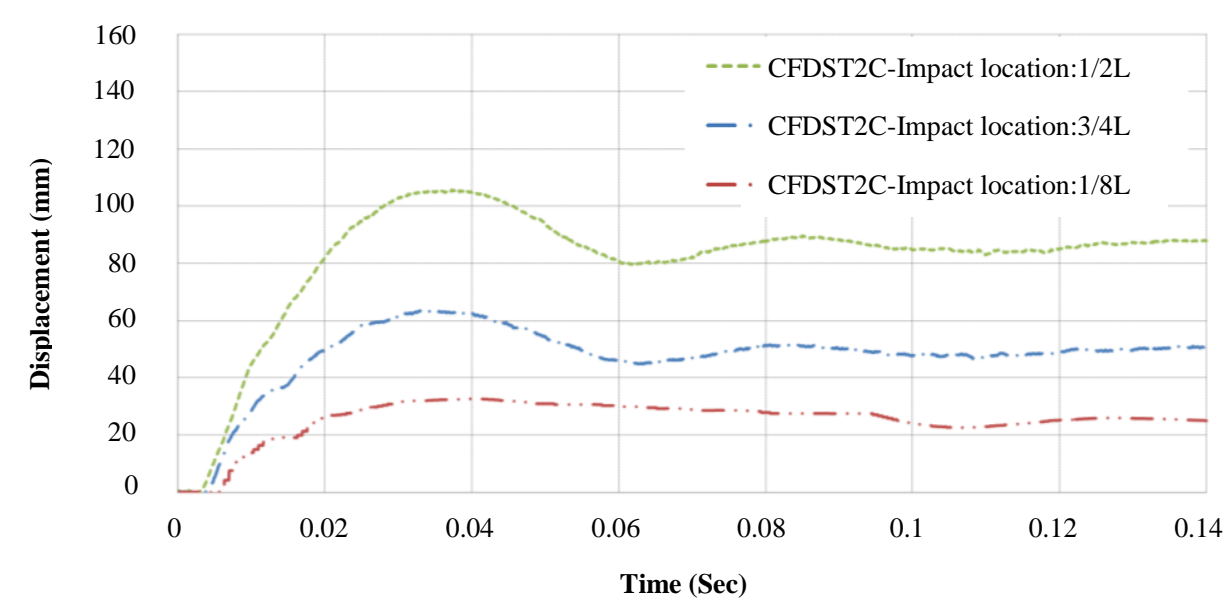

Fig 26 Global displacement-time history of test series\#3 specimen at different column locations

It is clear from Fig 25 that an increase in axial load results in an increase in the maximum and residual deflections. Additionally, shifting the impact location from mid-span towards one of the supports reduces the maximum and residual deflections. Fig 26 shows the global displacement-time histories of CFDST4B specimen at different locations along its length. Stress waves from the impact location take a finite time to propagate along the column and causes a time delay between the bending response of the column at impact point and that at the other locations.

\section{Permanent local buckling}

When the impact head strikes the CFDST specimen, very high strains develop around the impact zone, causing local buckling of the specimen. In this study, the local buckling after the impact is defined by three parameters: length, width and depth. These parameters are illustrated in Fig 27. Whilst a vernier calliper was used to measure the length and width of the local buckling, a depth gauge micrometre was employed to measure the local buckling depth. 

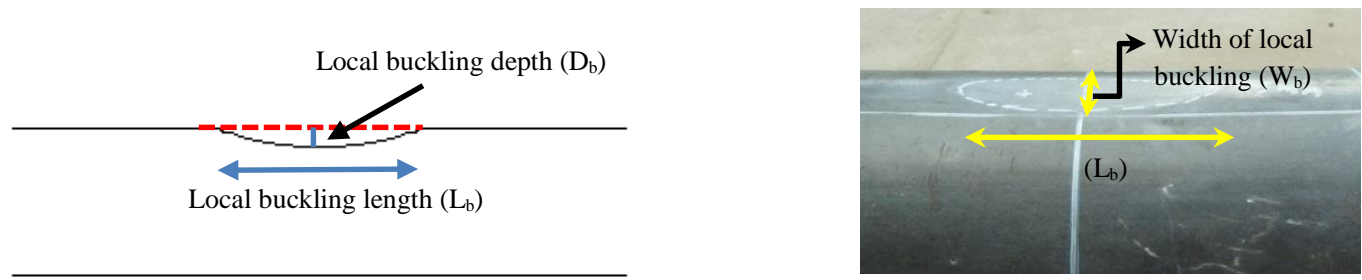

Fig 27 Illustration of terms that define the local bucking in an impacted CFDST column

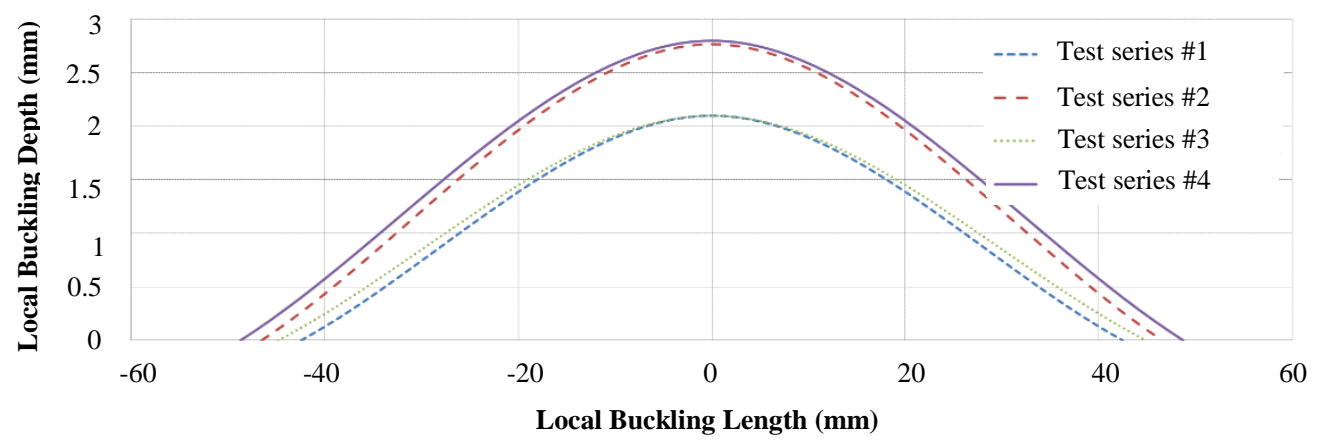

(a) local buckling depth vs. local buckling length

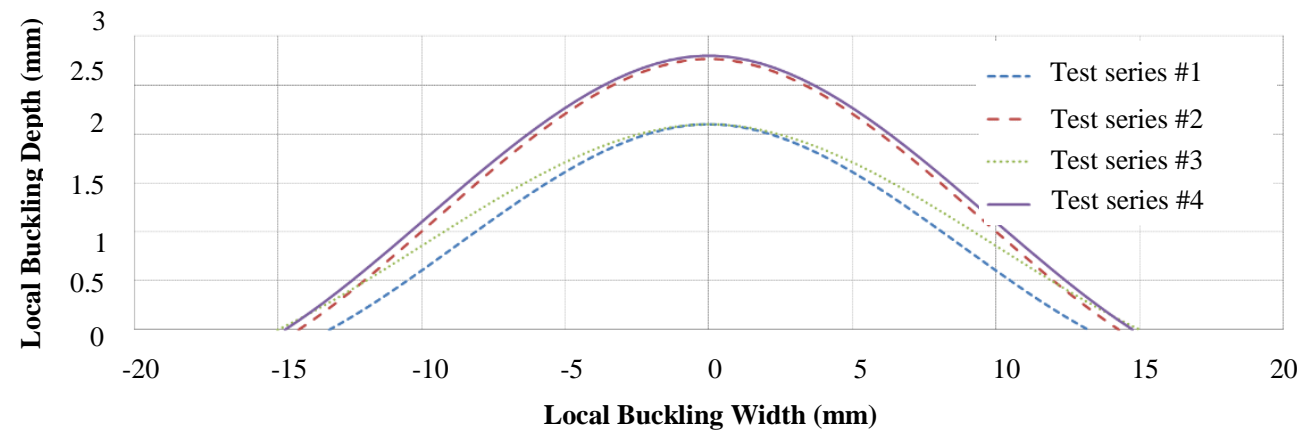

(b) local buckling depth vs. local buckling width

Fig 28 Permanent local deformation profile of specimens in different test series

Fig 28 shows the local buckling profile of CFDST specimens in the different test series. The zero values on horizontal and vertical axes of Fig 28a and Fig 28b represent the point of impact and the undamaged surface of the CFDST columns before impact, respectively. The values of length, width and depth parameters shown in Fig 28 are the average of measured values obtained from the tests with the same axial load and impact location combinations. With increase in the level of axial loading, the local buckling becomes more developed in the specimens. Shifting the impact location from mid-span towards the support reduces the length and depth of the local buckling and slightly increases its width. 


\section{Axial load-time histories}

Fig 29 shows the axial load-time histories of CFDST specimens during the impact tests. A degree of long-term drop can be seen and this was due to the shortening of the impacted column and system excitation in the axial direction. The axial load in an impacted member of a structural frame presents some changes [18]. Fig 29 shows this long-term drop in the axial load is greater under the higher axial load. It reaches $13.2 \%$ of the initial axial preloading in CDST4B with axial load of $400 \mathrm{kN}$. This was a result of the larger permanent shortening in this specimen caused by the lateral impact.

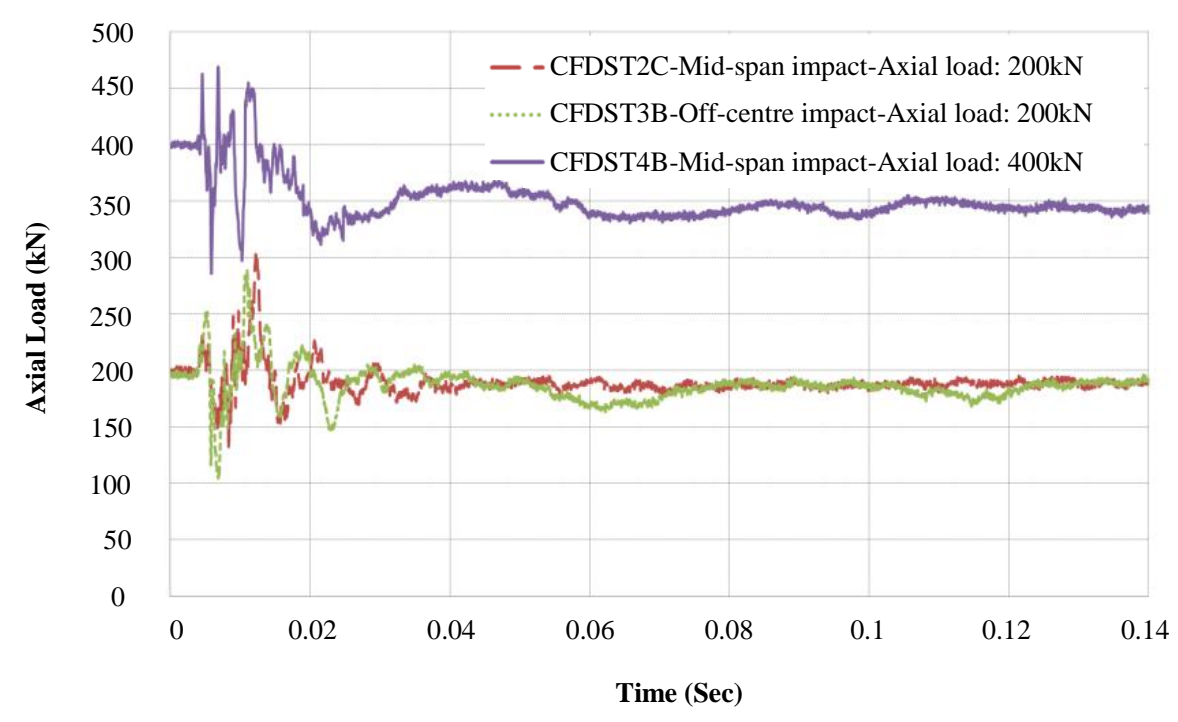

Fig 29 Axial load-time histories for test series\#2, \#3 and \#4

\section{Conclusion}

The performance of CFDST columns subjected to combined axial pre-loading and lateral impact was investigated through a series of experiments. An experimental method employing an innovative, compact, repeatable and costeffective horizontal impact testing system (HITS) capable of delivering up to $10.40 \mathrm{~kJ}$ of impact energy with a horizontal striker and applying and maintaining the axial load with a combination of disc-springs and parallel tension-rods was developed for this purpose. In total, eight specimens were tested, subjected to varying levels of axial load and impact locations. The new testing technique allowed to obtain useful information on the impact carriage velocity-time history, impact force-time history, total reaction force-time history, column global deflection-time history, column permanent local buckling profile, change of axial pre-loading during impact, and the response time lag. The results proved that the innovative HITS can successfully test structural columns under the combination of axial pre-loading and impact loading. It was also shown that introduction of a set of selfreacting system of disc-springs along with parallel tension-rods into the axial loading frame helps to effectively 
mitigate the possible axial load loss. The records of impact force-time history of the CFDST specimens showed four distinct phases: (1) the initial peak phase, (2) the vibration phase, (3) the plateau phase and (4) the unloading phase. Additionally, the results showed that the reaction force changes direction throughout an impact event. When the impact force wave associated with the initial peak phase reaches the supports, the reaction force sharply increases to a peak value in the direction of the applied impact force. As soon as the impact force wave associated with the vibration phase arrives, the reaction force changes its direction and reaches another peak value in the opposite direction. After this phase, the total reaction force reaches a plateau followed by a gradually decreasing phase until it approaches zero. It was observed that under lateral impact, CFDST columns undergo both global and local buckling. The physical inspection of the column after impact showed that the integrity of concrete was fairly good due to the effective confinement provided by outer and inner steel tubes. It was also found that axial load and impact location notably affect the response of the CFDST columns. An increase in axial load increases the maximum and residual deflections and causes the local buckling becomes more developed in the specimens. Additionally, the presence of the axial load results in reductions in the initial peak tensile force and the duration of the total reaction and causes an increase in the initial peak compressive force. Shifting the impact location from mid-span towards one of the supports reduces the deflections, the length and depth of the local buckling, the peak forces as well as the total reaction force duration and slightly increases the local buckling width. The results of the experimental study presented in this paper can be further used to validate the finite element model of CFDST columns subjected to lateral impact loading, which would then be confidently used as a viable alternative to experimental testing to carry out further investigation and analysis.

\section{Acknowledgements}

The authors would like to thank Mr. Anthony Morris and Mr. Mark Hayne for their continuous support in the experimental work. They also like to thank One Steel Mill Tube (Australia), HY-TEC concrete and Sika (Australia) for supporting this research by supplying the steel tubes, concrete and adhesive mortar, respectively.

\section{References}

1. Wei S, Mau ST, Vipulanandan C, Mantrala SK (1995) Performance of new sandwich tube under axial loading. Journal of Structural Engineering 121 (12):1814-1821 
2. Yagishita F, Kitoh H, Sugimoto M, Tanihira T, Sonoda K (2000) Double skin composite tubular columns subjected to cyclic horizontal force and constant axial force. Composite and Hybrid Structures:497-503

3. Li W, Han LH, Zhao XL (2012) Axial strength of concrete-filled double skin steel tubular (CFDST) columns with preload on steel tubes. Thin-Walled Structures 56 (9)

4. Corbett G, Reid S, Al-Hassani S (1990) Resistance of steel-concrete sandwich tubes to penetration. International Journal of Impact Engineering 9 (2):191-203

5. Li XH, Lei JP, Wang R (2013) Finite element analysis of concrete-filled double skin steel tubes with simply supported under lateral impact. Applied Mechanics and Materials 405:1106-1109

6. Wang Y, Qian X, Liew JR, Zhang M-H (2014) Experimental behavior of cement filled pipe-in-pipe composite structures under transverse impact. International Journal of Impact Engineering 72:1-16

7. Johnson GR (2001) Experimental and numerical investigation into impact bending collapse of rectangular hollow sections. University of Technology, Sydney,

8. Crupi V, Montanini R (2007) Aluminium foam sandwiches collapse modes under static and dynamic threepoint bending. International Journal of Impact Engineering 34 (3):509-521

9. Hanssen A, Enstock L, Langseth M (2002) Close-range blast loading of aluminium foam panels. International Journal of Impact Engineering 27 (6):593-618

10. Banthia N, Mindess S, Bentur A (1987) Impact behaviour of concrete beams. Materials and Structures 20 (4):293-302

11. Banthia N, Mindess S, Bentur A, Pigeon M (1989) Impact testing of concrete using a drop-weight impact machine. Experimental Mechanics 29 (1):63-69

12. Zhang X, Ruiz G, Yu RC (2010) A new drop-weight impact machine for studying fracture processes in structural concrete. Strain 46 (3):252-257

13. Zhang X, Ruiz G, Yu RC (2008) Experimental study of combined size and strain rate effects on the fracture of reinforced concrete. Journal of Materials in Civil Engineering 20 (8):544-551 
14. Liew JR, Sohel K, Koh C (2009) Impact tests on steel-concrete-steel sandwich beams with lightweight concrete core. Engineering Structures 31 (9):2045-2059

15. Kishi N, Mikami H, Matsuoka K, Ando T (2002) Impact behavior of shear-failure-type RC beams without shear rebar. International Journal of Impact Engineering 27 (9):955-968

16. May IM, Chen Y, Owen DRJ, Feng Y, Thiele PJ (2006) Reinforced concrete beams under drop-weight impact loads. Computers and Concrete 3 (2_3):79-90

17. Hobbs B, Gilbert M, Molyneaux T (1998) Effects of vehicle impact loading on masonry arch parapets. In: Arch bridges: history, analysis, assessment, maintenance and repair. Proceedings of the Second International Arch Bridge Conference.

18. Zeinoddini M, Parke G, Harding J (2002) Axially pre-loaded steel tubes subjected to lateral impacts: an experimental study. International Journal of Impact Engineering 27 (6):669-690

19. Allan J, Marshall J (1992) The effect of ship impact on the load carrying capacity of steel tubes. HM Stationery Office,

20. Yousuf M, Uy B, Tao Z, Remennikov A, Liew JR (2014) Impact behaviour of pre-compressed hollow and concrete filled mild and stainless steel columns. Journal of Constructional Steel Research 96:54-68

21. AS1391 (2007) Metallic mateials-tensile testing at ambient temperature. Standards Australia, North Sydney, N.S.W

22. AS1012.9 (1999) Methods of testing concrete-Determination of the compressive strength of concrete specimens. Standards Australia, North Sydney, N.S.W.

23. Han LH, Hou CC, Zhao XL, Rasmussen KJR (2014) Behaviour of high-strength concrete filled steel tubes under transverse impact loading. Journal of Constructional Steel Research 92:25-39 